$\oint_{\text {https://doi.org/10.3765/sp.13.9 }}^{\text {Semantics \& Pragmatics Volume 13, Article 9: 1-54, } 2020}$

\title{
Conjectural questions: The case of German verb-final wohl questions*
}

\author{
Regine Eckardt \\ University of Konstanz
}

Submitted 2018-10-26 / First decision 2019-01-09 / Revision received 2019-08-31 / Second decision 2019-12-22 / Revision received 2020-04-09 / Accepted 2020-06-15 / Published 2020-08-27 / Final typeset 2022-08-30

\begin{abstract}
The paper analyzes German verb-final questions with the particle wohl, which roughly translate as ' $Q$ I wonder?'. It construes German as an instance of a general typological pattern: Conjectural questions (CQs) are marked by evidentials in many languages, and German wohl is an inferential evidential. The analysis proceeds in three steps. First, wohl is shown to pattern with inferential evidentials in other languages. Declarative wohl $p$ asserts $p$ and conveys 'the speaker defeasibly infers $p$ from secure knowledge' as non-at-issue content. Second, the analysis is extended to standard wohl $Q$ questions, accounting for the interrogative flip. Third, the analysis integrates conjectural verb-final wohl questions. I propose that CQs ask for answers that are defeasibly entailed by the pooled knowledge of speaker and addressee. Due to the logic of defeasible inference, the addressee is not in a position to answer the CQ unless both interlocutors have pooled their knowledge. In normal utterance contexts, these questions are thus un-answerable. We see two conventionalized reactions: the interlocutors engage in speculative discourse, or the $\mathrm{CQ}$ is understood as a statement of curiosity that doesn't require a response.
\end{abstract}

Keywords: evidentials, interrogative flip, defeasible inference, speaker orientation, indexicals

* I want to thank Gisela Disselkamp, Andrea Beltrama, Donka Farkas, Sven Lauer, Maribel Romero and the audiences at the ExPrag Workshop Oslo 2017 and CSSP Paris 2018, as well as Judith Tonhauser, Kai von Fintel and two anonymous reviewers for their valuable comments and questions. All remaining errors are my responsibility. Research was funded by the DFG as part of the RU 2111 Konstanz, which I gratefully acknowledge.

(C)2020 Regine Eckardt

This is an open-access article distributed under the terms of a Creative Commons Attribution License (https://creativecommons.org/licenses/by/3.o/). 
Regine Eckardt

\section{Introduction}

The paper aims to analyse the following contrast between standard questions and conjectural questions (CQs) in German.

(1) Wo ist der Schlüssel? where is the key

'Where is the key?'

(2) Wo wohl der Schlüssel ist? where wohl the key is

'Where might the key be, I wonder.'

(1) conveys a standard question. In uttering it, the speaker requests the addressee to answer. (2) expresses that the speaker is asking herself or wondering. Even if an addressee is present, (2) does not request the addressee to answer. Conjectureal questions like (2) are therefore also described as self-addressed, deliberative, monological or "questions in the absence of an addressee". In terms of syntax (2) differs from (1) in two respects. (2) shows German subordinate clause syntax with the finite verb in sentence-final position. Moreover (2) contains the particle wohl and (1) doesn't. The particle is mandatory in wh-questions to achieve the CQ reading, as (3) shows.

(3) \# Wo der Schlüssel ist where the key is Unavailable 'Where might the key be, I wonder.'

There is a considerable body of research on German verb-final questions (Altmann 1987, Oppenrieder 1989, Lohnstein 2007, Truckenbrodt 2006, Gutzmann 2011, M. Zimmermann 2013). Lohnstein and Truckenbrodt maintain that the verb-final syntax of (2) suffices to trigger the conjectural reading, a view that is challenged by constituent questions like (3).

The particle wohl marks declaratives as "uncertain knowledge" and its contribution to CQs has remained unexplored so far. Taking a look at CQs at large, we find a broad range of languages where evidential markers serve to indicate CQs, including languages as diverse as Japanese (Japonic; Hara 2006), Gitksan, St'át'imcets and Nełe?kepmxcín (Salish; Littell, Matthewson \& Peterson 2010, Peterson, Sauerland \& Déchaine 2010), Italian (Eckardt \& Beltrama 2019), Basque (isolated; Trotzke \& Monforte 2019), Shipibo-Konibo (Panoan, Peru; Valenzuela 2003) and Cheyenne (Algonqian; Murray 2010a: 
p. 113). The respective evidential markers express uncertain knowledge or inferential evidentiality in declarative sentences. It thus seems attractive to explore the parallels between wohl in German verb-final questions, and evidentials in CQs in general.

The present paper pursues the hypothesis that German wohl verb-final questions are an instance of this general typological pattern. We proceed in three steps. First, I argue that wohl in declaratives is an inferential evidential (Willett 1988). Second, I extend the account to wohl in standard questions and in step three propose how wohl contributes to derive the conjectural question reading for questions like (2).

The paper is structured as follows: Section 2 argues that wohl in declarative sentences like (4) is an inferential evidential.

(4) Der Schlüssel ist wohl im Auto.

The key is wohl in.the car

'The key is in the car, I assume'

While the translation in (4) follows M. Zimmermann 2004, 2008, I argue that his analysis must be refined. I propose that the declarative sentence wohl $p$ conveys that the prejacent $p$ is defeasibly entailed by the speaker's knowledge. The proposition $p$ is presented not as secure knowledge but as a reasonable assumption by the speaker. Defeasible entailment is captured in a Lewis-Kratzer analysis in terms of possible worlds.

Section 3 discusses the particle wohl in standard questions like (5).

(5) Wo ist wohl der Schlüssel? where is wohl the key

'Where, do you assume, is the key?'

In (5) wohl is reoriented to the addressee and asks about her assumptions and inferences (M. Zimmermann 2004). This reorientation has been called the 'interrogative flip' and occurs frequently though not universally. ${ }^{1}$ While Korean questions with evidentials show the flip reading (Lim 2011), Samoyedic languages do not allow evidentials in questions (Künnap 2002: p. 149). A comprehensive survey suggests that the interrogative flip follows from specific properties of individual evidentials rather than universal pragmatic reasoning.

1 The term goes back to Tenny \& Speas 2004 who refer to Speas \& Tenny 2003, though the term was not explicitely introduced in the earlier paper. 
Regine Eckardt

Section 4 starts out by demarcating the meaning of standard questions, standard wohl questions and verb-final wohl questions. The latter express CQs, and I detail their pragmatic profile in 4.1. The analysis in 4.2 proposes that CQs like (2) are conventionalized from a generalized use of the inferential evidential wohl:

- In declaratives, wohl is oriented to the speaker and reports the speaker's inferred beliefs.

- In standard questions, wohl is oriented to the addressee and asks for the addressee's inferred beliefs.

- In CQs, wohl is oriented to speaker $\oplus$ addressee. The meaning of wohl entails that the addressee cannot answer the CQ unless both interlocutors have pooled their knowledge on question $Q$. We find two conventionalized possible reactions: the addressee can remain silent or engage in speculative discourse.

The envisaged analysis aims to treat a specific case - German verb-final wohl questions - in a way that aligns with typological trends at large. Section 5 sketches how the proposed analysis can be applied to other languages.

\section{Evidential wohl in declarative sentences}

The present section investigates wohl in declarative sentences. I abbreviate these as wohl $p$ and refer to $\mathrm{p}$ as the prejacent. The discussion of data in Section 2.1 is divided in two parts. 2.1.1 submits wohl $p$ to the series of tests by Faller (2002) that separate evidentials from other sentential modifiers. The data confirm that wohl patterns with evidentials and differs from modals. Section 2.1.2 investigates the semantic content of wohl, offering more evidence in favour of a treatment as an inferential evidential. I argue that wohl expresses defeasible inference and inference based on subjective experience. Section 2.2 offers a formal analysis. The main novel element is an implementation of subjective defeasible inference in terms of possible world semantics. ${ }^{2}$ We also address the scope taking behaviour of wohl and the divi-

2 There is no inherent conflict between wohl being an inferential evidential and its content being analysed in terms of possible worlds. The nature of wohl is determined by semantic content, position at LF and the allocation of content as at-issue and non-at-issue content. These factors account for the differences to modals like might or adverbs like probably. 
Conjectural questions

sion into at-issue and non-at-issue content. Section 2.3 tests the predictions against the data.

\subsection{Data}

Evidentials can be characterized in two ways. Some authors maintain that evidentials are primarily characterized by their semantic content (Matthewson, Davis \& Rullmann 2007, Korotkova 2014, 2017). Others assume that a typical profile of scope taking, embedding, and projection properties is essential. Both sets of diagnostics will be applied to wohl, with 2.1.1 devoted to Faller's tests and 2.1.2 probing the semantic content of wohl.

\subsubsection{Tests for evidentiality}

This subsection discusses the properties of wohl with respect to Faller's (2002) tests for evidentials, in their adaption by Matthewson, Davis \& Rullmann 2007 in (6). ${ }^{3}$

(6) i. (In)felicity if prejacent is known to be true

ii. (In)felicity if prejacent is known to be false

iii. Scope-taking under negation and in questions

iv. Assent/dissent

v. Embedding in if-clauses

vi. Readings in (standard) interrogatives

vii. Indirect evidence not cancellable

The tests assess basic scope taking, consistency and projection properties of an item and allocate data points that help to distinguish between different analyses. In particular, potential evidential markers are compared to modals and presupposition triggers by their scope taking behaviour and projection properties.

\section{i. (In)felicity if prejacent is known to be true}

M. Zimmermann $(2004,2008)$ observes that declarative wohl $p$ is infelicitous if the speaker knows for certain that $p$, as shown in (7) and (8).

3 The test for (in)ability to raise assertive strength does not apply here. 
Regine Eckardt

(7) Hein ist wohl auf See.

Hein is wohl on sea

'Hein is at sea, I assume.'

(8) \# Ich weiß wo Hein ist: Hein ist wohl auf See.

I know where Hein is Hein is wohl on sea

Unavailable: 'I know where Hein is: Hein is wohl at sea.'

While (7) is a perfectly natural utterance, (8) is incoherent because, as Zimmermann argues, the embedding predicate know is incompatible with uncertainty conveyed by wohl. According to Zimmermann, wohl $p$ conveys that speaker $x$ assumes that $p$ and that $\operatorname{ASSUME}(x, p)$ is a weaker commitment than $\operatorname{KNOW}(x, p)$. By and large, wohl $p$ is infelicitous if the speaker knows for certain that the prejacent is true.

However, Göbel's paradox challenges this generalization (Göbel 2017, 2018). He points out that the speaker in (9) can use wohl $p$ although he knows $p$ for certain (example inspired by Göbel 2017: (8), Göbel 2018: (5), (6)).

(9) A: Athens is in Turkey, as we all know.

B: No, look at this map. It clearly shows that Athens is in Greece.

A: Da hab ich mich wohl geirrt. there have I me wohl erred

'Obviously I've been wrong.'

In the given situation, the speaker knows perfectly well that he has been wrong. We'd hence expect that wohl $p$ is inadequate. In fact it is not. According to Göbel's intuition - with which I agree - A presents $p$ 'Obviously I've been wrong' as an inference that rests on (a) A's earlier claim and (b) the evidence supplied by B. ${ }^{4}$

In summary, wohl $p$ is infelicitous when the prejacent $p$ is known to be true and thus patterns with inferential evidentials. Exceptions are possible when the speaker intends to highlight that $p$ is inferred knowledge. The analysis of wohl has to reconcile the general pattern illustrated in (7) and (8) with Göbel's paradox in (9).

4 A reviewer raises the question whether mirativity may play a role (Peterson 2016). This is not the case. If A wanted to express surprise he'd have to use hoppla, ach! or other mirative elements. Examples in Göbel 2018 likewise refute an explanation in terms of mirativity. 
Conjectural questions

\section{ii. (In)felicity if prejacent is known to be false}

If a declarative with wohl is conjoined with the negated prejacent, the result is incoherent. Exchanging the coordination und 'and' by contrastive aber 'but' doesn't improve the example.

(10) \# Hein ist wohl auf See, und/aber er ist nicht auf See.

Hein is wohl at sea and/but he is not at sea

Unavailable: 'Hein could be at sea, and/but actually he isn't at sea.'

There is no conceivable context that would render (10) acceptable. This shows that the speaker who utters wohl $p$ is committed to $p$. The particle wohl thus differs from existential modals like could as well as certain hearsay evidentials (e.g., Cheyenne séste, Murray 2009, 2010a). It patterns with inferential evidentials and eye-witness evidentials which express that the speaker is committed to the truth of the prejacent.

\section{iii. Scope-taking under negation and in questions}

M. Zimmermann (2004, 2008) demonstrates that wohl always takes highest scope over negation and question formation. (11) illustrates the case of negation.

(11) Hein ist wohl nicht auf See.

Hein is wohl not at sea

'I assume that Hein is not at sea.'

(11) conveys that the speaker assumes that Hein is not at sea. It does not have a reading where the speaker negates an assumption or inference. (11) is unsuited to express “I don't assume that 'Hein is at sea' (but I know that he is)". This shows that wohl takes scope over negation.

Similarly, wohl takes scope over question operators (M. Zimmermann 2008). (12) only has the reading in (13a) where wohl scopes over question formation. The putative reading (13b) where wohl is in the scope of question formation is unavailable.

(12) A to B: Ist Hein wohl auf See?

Is Hein wohl at sea

(13) a. $\quad\{$ B assumes (Hein is at sea), B assumes (not (Hein is at sea)) $\}$ 
b. Unavailable:

$\{\mathrm{B}$ assumes (Hein is at sea), not( B assumes (Hein is at sea)) $\}$

Zimmermann illustrates the intuition with the ill-formed dialogue in (14).

(14) A: Ist Hein wohl auf See?

'Is Hein wohl at sea?'

B: \# Nein, ich nehme nicht an, dass Hein auf See ist.

No I assume not prt that Hein at sea is.

Unavailable: 'No, I don't assume that Hein is at sea.'

In summary, wohl takes high scope over negation and question formation.

\section{iv. Assent/dissent}

Faller's tests for assent and dissent are designed to reveal which parts of an utterance are explicit proposals for a common ground update. The data show that assent and dissent target the prejacent of wohl. The content of wohl, 'the speaker assumes $p$ ', can not be targeted by assent/dissent.

(15) A: Hein ist wohl auf See.

'Hein is at sea, I suppose/infer.'

B: Nein, das stimmt nicht.

'No, that's not true.'

a. Er ist nicht auf See.

'He is not at sea.'

b. \# Das nimmst Du nicht an.

Unavailable: 'You do not suppose this.', 'You do not infer this.', 'This can not be supposed.'

(15a) shows that B can deny the prejacent. The reply cannot target A's evidence or level of certainty, as shown in (15b). The same holds true for assenting replies. B's answer in (16) targets the prejacent 'Hein is at sea'.

(16) A: Hein ist wohl auf See.

'Hein is at sea, I suppose.'

B: Ja, das stimmt.

'Yes, that's true.' 
Conjectural questions
a. Er ist auf See.
'He is at sea.'
b. \# Das nimmst Du an / Das kannst Du schließen.
Unavailable: 'You assume this.', 'You infer this.'

(16a) confirms that B can agree to the prejacent. To see the point of (16b) we must consider a situation where (i) B agrees that A may have reason to infer $p$ but (ii) B knows that $p$ does not hold true. This is illustrated in (17).

(17) A and B pass by Hein's house, locked and shutters closed. B happens to know that Hein is in Munich. A, however, concludes on basis of his evidence:
A: Hein ist wohl auf See.
'Hein is at sea, I suppose.'
B: \# Ja, das stimmt.

Unavailable: 'Yes, that's true. You may suppose that Hein is at sea.'

The use of wohl $p$ hence differs from might $p$ in mastermind scenarios, where B could agree to A's inference in (17). ${ }^{5}$

The assent/dissent test allows us to conclude that "the speaker supposes or infers $p$ " is non-at-issue content and not accessible as target of replies (Murray 2014). Wohl patterns with inferential evidentials in other languages and differs from modal might and must.

\section{v. Embedding under conditionals}

Various authors observe that the use of wohl in the antecedent of a conditional is unacceptable (Krifka 2004, reported in Faller 2006, M. Zimmermann 2008). This is illustrated in (18).

(18) \# Wenn Hein wohl auf See ist, dann kochen wir Spaghetti.

If Hein wohl at sea is, then cook we spaghetti

Unavailable: 'In case that we suppose that Hein is at sea we'll cook spaghetti.'

(18) is possible if construed as factual conditional, as in (19). Imagine that A has just mentioned Hein ist wohl auf See 'Hein is at sea, I suppose'.

5 Von Fintel \& Gillies 2011 discusses the paradigm in detail. 
Regine Eckardt

(19) Wenn Hein wohl auf See ist, dann kochen wir Spaghetti.

If Hein wohl at sea is, then cook we spaghetti

Factual conditional: 'Given that you assume/infer that Hein is at sea, we'll cook spaghetti.'

The speaker in (19) presupposes that the antecedent is true, which leads to a factual conditional reading (Iatridou 1991). We will return to this effect later.

\section{vi. Readings in standard interrogatives}

M. Zimmermann $(2004,2008)$ describes the interrogative flip for wohl in questions like (20).

(20) Wo ist Hein wohl?

Where is Hein wohl

'What is your guess: where is Hein?'

(20) asks about the addressee's assumptions or inferences about Hein's whereabouts. Zimmermann takes particular care to demonstrate the change in orientation from speaker to addressee. Exam questions reveal that wohl in questions is not a marker of speaker uncertainty. A teacher, knowing the answer perfectly, can still ask a weak student (21).

(21) Was ist wohl die Hauptstadt von Frankreich?

What is wohl the capital of France

Teacher to student: "What is the capital of France ( - and you may have to guess)?"

This confirms the interrogative flip for wohl in questions.

Evidential markers don't pattern uniformly in questions. San Roque, Floyd \& Norcliffe (2017) report on languages that prohibit the use of evidentials in questions, and questions with evidentials that have only a CQ reading. German wohl is special in that it exhibits the flip reading in standard questions and the conjectural reading in verb-final wohl questions.

\section{vii. Indirect evidence not cancellable}

A final test concerns the question whether the content of wohl can be retracted. If this were the case, an analysis as pragmatic implicature would be 
Conjectural questions

warranted. However, the data confirm that, unlike implicatures, the content of wohl can not be cancelled.

(22) \# Ich sehe Hein dort auf der Cutty Sark, die gerade ausläuft. Hein ist wohl auf See.

Unavailable: 'I can see Hein right there sailing on the Cutty Sark: Hein is at sea.'

The first sentence presents $p$ 'Hein is at sea' as directly witnessed. Direct perception counts as stronger evidence for $p$ than assuming or inference. The second sentence conveys that the speaker infers or supposes 'Hein is at sea'. If this came about by scalar implicature, we would expect that the implicature can be cancelled and the discourse is coherent. In fact, it is marked. Example (22) thus shows that the content of wohl $p$ does not come about by conversational implicature (pace Hara's (2018) account of Japanese daroo in assertions and questions in terms of implicature).

In summary, the tests show that wohl patterns with evidentials in other languages and differs from modals. However, its scope taking and projection behaviour is not sufficient to unveil wohl as inferential evidential, as wohl shares scopal properties with German particles in general (M. Zimmermann 2011). The hypothesis that wohl is an inferential evidential must thus build on more specific data. These are reviewed in the next subsection.

\subsubsection{Specific observations about wohl $p$ declaratives}

We start from M. Zimmermann (2004, 2008) who posits that wohl $p$ is analyzed as "the speaker $x$ assumes $p$ ": $\operatorname{ASSUME}(x, p)$. The lexical content of ASSUME is left vague and could subsume belief with a high probability, belief without verification, belief by faith or other epistemic relations. Once we review possible and impossible uses of wohl, it becomes clear that the lexical content of wohl p is more specific. Göbel's paradox in 2.1.1 is a first challenge but not the only one.

Wohl does not express high likelihood

Zimmermann potentially includes cases where $x$ assumes $p$ because $x$ knows that $p$ is highly likely. His analysis predicts that wohl $p$ is acceptable in such situations. In actual fact, however, it is not. Consider the following scenario: $\mathrm{A}$ is requested to draw a marble from a box that contains one black and 
nine white marbles. A knows this and has now drawn a marble but can not see its colour yet. In this situation (23a) is inappropriate whereas (23b) is an appropriate utterance.

$$
\begin{aligned}
& \text { a. \# Ich habe wohl eine weiße Murmel gezogen } \\
& \text { I have wohl a white marble drawn } \\
& \text { b. Ich habe wahrscheinlich eine weiße Murmel gezogen } \\
& \text { I have probably a white marble drawn } \\
& \text { 'I have probably drawn the white marble.' }
\end{aligned}
$$

Native speakers share the intuition that wohl $p$ is inappropriate to express that the speaker holds $p$ as statistically likely. The situation in (23) lacks witnessed facts that allow the speaker to infer $p$. In order to explain why (23a) is inappropriate we must get a better understanding what counts as witnessed facts and how these license inferences.

The notion witnessed fact is easy to illustrate but difficult to define. In example (17), the witnessed facts in play are $q_{1}=$ 'Hein's house is locked' and $q_{2}=$ 'the shutters are closed'. Witnessed facts often coincide with what counts as "direct evidence" in languages that lexify this category. Suitable evidence improves example (23a): Assume that a bystander C observes A's drawing and can see the result. If A sees C's unsurprised face he can infer that the result of the drawing was unsurprising, i.e. as likelihood suggested. In this alternative scenario A has witnessed facts in favour of $p$ and (23a) is acceptable. ${ }^{6}$

The nature of inferencing is the second factor in play. The next sections argue in favour of defeasible inference. (23a) shows that defeasible inferences are not the same as likelihoods. The particle wohl is not synonymous to likely, highly likely or almost certainly and the relation ASSUME is too unspecific to account for this observation.

\section{Defeasible inference from speaker's knowledge}

This section discusses an example where all factors behind the wohl $p$ inference are explicit. Consider a situation where A and B wonder where Granny might be. A knows the following.

(24) $\quad q_{0}: \quad$ It is Friday afternoon.

$q_{1}$ : Granny often goes shopping on Friday afternoon.

6 Thanks to Sven Lauer (p.c.) who brought up this example. 
Conjectural questions

$$
\begin{array}{ll}
q_{2}: & \text { Her shopping bag and purse are missing. } \\
q_{3}: & \text { Her slippers are in the hall. }
\end{array}
$$

While $q_{0}$ and $q_{1}$ are general world knowledge, $q_{2}$ and $q_{3}$ are witnessed facts. In view of her knowledge, A utters (25).

(25) A: Oma ist wohl einkaufen gegangen.

Granny is wohl shopping gone

'Granny went shopping, I suppose'

By using wohl, A conveys the following complex message:

(26) The issue at hand is "Where is Granny?".

The relevant facts I know $\left(q_{0}-q_{3}\right)$ lead me to infer $p=$ 'Granny went shopping'.

Further facts may force me to withdraw my conclusion.

A's claim rests on A's body of relevant knowledge $q_{0}-q_{3}$ about Granny's whereabouts. Yet $q_{0}-q_{3}$ are just indications, not a logical proof for $p$. If A finds out later that $q_{4}=$ 'Granny's Wellingtons are missing' (which she never wears downtown) she will withdraw the inference and conjecture that Granny went searching for mushrooms.

Inferences of this kind were studied as defeasible inferences in AI (Gabbay, Hogger \& Robinson 1994, Strasser \& Antonelli 2016), and are illustrated by the Tweety example. When I know that 'Tweety is a bird', I am likely to infer 'Tweety can fly'. If I learn 'Tweety is a penguin' in addition, I no longer infer 'Tweety can fly'. More knowledge can defeat earlier inferences.

Let us take a closer look at the knowledge behind wohl-inferences. For one, it is a limited body of knowledge. Speaker A may be an expert in nuclear physics but her knowledge about nuclear physics is irrelevant for (25). Moreover, it includes witnessed facts (like Granny's missing bag). Sensory evidence also counts as witnessed fact. An experienced cook could take a look at cookies in the oven and state Sie sind wohl fertig ('they are wohl finished') based on the witnessed fact $q=$ their smell and colour.

Another kind of witnessed fact brings wohl $p$ close to hearsay evidentials. This is illustrated in (27).

(27) Hein's wife talking to A: Hein ist gerade auf See. Hein is just at sea. 'Hein is at sea right now' 
Regine Eckardt

\section{A, later to B: Hein ist wohl auf See. \\ Hein is wohl at sea. \\ 'Hein is at sea, I hear.'}

At first glance (27) looks like a hearsay evidential (A has heard that $p$ ) but this is not what is conveyed. At the back of A's mind is knowledge as $q_{1}=$ Hein's wife said that he's at sea, $q_{2}=$ she is usually trustworthy and $q_{3}=$ she should know where Hein is. A defeasibly infers from $q_{1}, q_{2}$ and $q_{3}$ that Hein is at sea. The same overlap between reportative and inferential evidentials was pointed out for Cheyenne (Murray 2010b).

The common pattern behind all examples is this: The speaker knows witnessed facts $q$. These do not offer conclusive evidence for prejacent $p$ but regarding the issue $Q$ at hand ("where is Hein?", "What is Granny doing?"), $q$ is sufficient for the speaker to tentatively infer $p$. Lastly, the inference rests on the maximal set of relevant facts known to the speaker. For instance, if speaker A in (26) knew in addition that $q_{4}=$ 'Granny's wellingtons are missing' she would no longer infer 'Granny went shopping' even though she still knows $q_{0}-q_{3}$.

Inference from witnessed facts resembles what von Fintel \& Gillies (2010) call inferences from privileged knowledge in their analysis of epistemic must in English. They analyse epistemic must $p$ as inference from kernel $K_{a}$, the set of privileged knowledge of agent $a$. Likewise, Murray (2010b) assumes that the "kernel of information, evidence" is the source of information for inferential evidentials in Cheyenne. I leave the exact alignment of these terms for another occasion and conclude with the following diagnosis: Wohl $p$ expresses that $p$ is an uncertain inference that rests on secure knowledge $q$.

\section{Requests to explicate evidence}

Declaratives wohl $p$ permit the interlocutor to ask for evidence more naturally than plain assertions $p$. A plain declarative sentence conveys that the speaker has sufficient evidence to make an assertion. Declaratives with wohl not only convey uncertainty but invite 'Why do you think so?' as a natural reaction. ${ }^{7}$ Imagine that colleague A opens conversation with B on Monday morning by either (28) or (29).

(28) A: Hein ist wohl krank. Hein is wohl ill

7 I thank Ramona Wallner who first made this observation. 
Conjectural questions

$$
\begin{aligned}
& \text { 'Hein is ill, I assume.' } \\
& \text { B: Warum glaubst Du das? } \\
& \text { Why believe you that } \\
& \text { 'Why do you believe so?' } \\
& \text { (29) A: Hein ist krank. } \\
& \text { Hein is ill } \\
& \text { 'Hein is ill.' } \\
& \text { B: Warum glaubst Du das? } \\
& \text { Why believe you that } \\
& \text { 'Why do you believe so?' }
\end{aligned}
$$

In the dialogue in (28), B can take up A's cue wohl and ask for A's evidence. In (29), B's reaction suggests that she doesn't consider A as trustworthy. Given that A offered no reason for doubt, B's reaction is slightly offensive. ${ }^{8}$ In (28), B's asking back seems invited by A's using wohl. It is not offensive to refer to $p$ as a belief rather than certain knowledge.

(30) and (31) confirm this semantic contrast. While the short reply why in (30) can only be interpreted in one way, (31) allows two equally natural interpretations.

(30) A: Hein ist krank. - B: Warum?

A: 'Hein is ill' - B: 'Why?'

Interpretation: 'Why is Hein ill.'

(31) A: Hein ist wohl krank. - B: Warum?

A: 'Hein is wohl ill' - B: 'Why?'

Interpretation a. 'Why do you believe this?'

Interpretation b. 'Why is Hein ill?'

As (31) shows, wohl $p$ highlights that A has reasons to infer $p$. Reacting to the plain assertion (30), B uses why? to ask for reasons of Hein's illness. No second reading is available. A similar contrast between declaratives with and without inferential evidential was described for Cheyenne in Murray 2010b, 2016.

8 A reviewer points out that the differences in impoliteness are gradual and there is no clearcut divide between polite versus impolite cases of asking back. If A claims something totally implausible that B finds hard to believe then B will ask A for their evidence, no matter whether A uses wohl or not. 
Regine Eckardt

\section{Subjective inference}

A final contrast shows that wohl $p$ indicates subjective inference. This becomes clear when we consider defeasible inferences that are part of an objective scientific theory. Medical diagnoses are defeasible inferences from a set of symptoms. Given that wohl signals defeasible inference, we would expect that the use of wohl is appropriate in medical diagnoses. In actual fact, it is not, as the measles example (32) shows: Assume that the symptoms patient has red spots, fever and sore throat justify the medical diagnosis patient has the measles. Nevertheless, the doctor in (32a) expresses a personal estimate ("according to my experience"). (32b) should be used to convey the medical diagnosis properly.

(32) Doctor summarizing the patient's symptoms: Sie haben rote Punkte, Halsweh und Fieber. ('You have red spots, a sore throat and fever.') ${ }^{9}$

a. Sie haben wohl die Masern.

You have wohl the measles

'I suppose that you have the measles.'

b. Sie haben die Masern.

You have the measles

'You have the measles, I diagnose.'

The speaker in (32a) suggests that other persons, faced with the same facts, might draw different conclusions. The speaker in (32b) conveys that the assertion is supported by medical science. The contrast between diagnosis and personal estimate shows that wohl $p$ indicates inferences $p$ that rest on the speaker's personal experience. The contrast systematically arises in situations where experts assert defeasible inferences in a scientific framework, as in weather forecasting or when identifying a specimen. Wohl $p$ inferences are hence subjective in several respects:

- $p$ follows defeasibly from the speaker's privileged knowledge $q$.

- If the speaker learns more, he may be justified to utter wohl $p$ at time $\mathrm{t}_{1}$ but no longer at a later time $\mathrm{t}_{2}$ (modified ex. (25) wellingtons).

- The same witnessed fact can entail $p$ for one speaker but not for others (see (32)).

9 While several speakers agreed, one reviewer doesn't share the judgement. 
Conjectural questions

The analysis of wohl, to which we now turn, should account for these subjective aspects.

\subsection{Analysis}

\subsubsection{Earlier accounts}

There are to date two formal treatments of wohl in declaratives. M. Zimmermann (2008) proposes that wohl denotes $\lambda p \operatorname{ASSUME}(x, p)$ where the predicate $\operatorname{ASSUME}(x, p)$ is true iff $x$ assumes that $p$ is true. ${ }^{10}$ ASSUME contrasts with KNOW and indicates belief with less confidence than KNOW. The scope-taking properties of wohl are predicted by assuming that wohl is situated in SpecForceP at LF, thus taking high scope over negation, question and focus operators. Syntactic heads $\operatorname{decl}_{s p}$ and int $t_{a d}$ in ForceP serve to anchor $x$ to speaker or addressee in declaratives and questions by spec-head agreement. Wohl composes with the sentence denotation late, which predicts its taking high scope. M. Zimmermann (2004, 2008, 2011) argues against an analysis in terms of conventional implicatures (Potts 2005) or a separation in terms of assertion versus presuppositions. He considers wohl to be a speech act operator that updates the common ground CG by ASSUME(speaker, $p$ ) (M. Zimmermann 2008: p. 216). The addressee is invited to believe $p$ if he shares the speaker's assumption. If the addressee expresses doubt the CG maintains the information that $s p$ assumes that $p$. Alternative analyses in terms of a lowered threshold of reliability (Davis, Potts \& Speas 2007, McCready \& Ogata 2007) are mentioned but not further pursued (M. Zimmermann 2011).

While Zimmermann successfully predicts scope-taking and the interrogative flip in standard questions, his relation ASSUME is too unspecific to account for the inferential content of wohl. The properties of wohl $p$ in the assent/dissent test remain unaccounted for; specifically it is open why reactions can target the prejacent $p$. Finally, the account in its present form does not extend to conjectural questions with wohl.

Göbel (2017, 2018) challenges Zimmermann's analysis on basis of Göbel's paradox in (9), from which he concludes that wohl $p$ presents $p$ as an inference. He analyses the content of wohl in terms of a predicate $\operatorname{INF}\left(v_{0}, \mathrm{i}, p\right)$, which he paraphrases as 'the individual i infers $p$ at index $v_{0}$ '. While this resonates with the present analysis, Göbel fails to spell out the logical content of INF. According to his paraphrase, German wohl could be synonymous to

10 Notation slightly adapted. 
English epistemic must, which fails to acknowledge the defeasible and subjective nature of wohl inferencing. ${ }^{11}$

A final precursor of the present paper is Kratzer 1991 where must $p$ is analysed as asserting $p$ with a lower level of certainty than plain assertion (pace von Fintel \& Gillies 2010). While her analysis resembles the present proposal, the division of labour differs in detail. Kratzer assumes that must $p$ presents $p$ as uncertain because $p$ follows by logical (i.e. reliable) inference from unreliable belief. The utterance wohl $p$, in contrast, presents $p$ as uncertain because it follows from reliable knowledge by defeasible (i.e., unreliable) inference. Due to this fundamental difference, our implementation deviates from Kratzer's classical anaysis of must in detail.

\subsubsection{Defeasible inference}

I propose that wohl is an inferential evidential that expresses defeasible inference. The present section develops an analysis in terms of possible worlds, in the tradition of Lewis 1973, Kratzer 1991.

The underlying idea is the following. Assume that agent A knows in $w_{0}$ that proposition $q$ holds true. Hence A knows that she is in one of the $q$ worlds. In some of these, $q$ is true under circumstances that match A's expectations about $q$-worlds - these I call stereotypical $q$-worlds (as to A's experience in $w_{0}$ ) - but in others, $q$ is true under circumstances that A considers as non-normal. For instance, assume that A knows $q=$ 'Tweety is a bird'. A knows that birds include flying birds and non-flying birds like penguins. But if pressed, A will tentatively assume that Tweety is a flying bird. In other words, worlds where Tweety is a flying bird are stereotypical 'Tweety is a bird'-worlds for A whereas worlds where Tweety is a penguin or an ostrich are not. ${ }^{12}$

I propose to capture this idea by the relation STEREO.

(33) Let STEREO be a relation on $D_{e} \times D_{s} \times D_{\langle s, t\rangle} \times D_{s}$ with the following truth conditions: For any individual A, world $w_{0}$ and proposition $q$,

STEREO(A, $\left.w_{0}, q, w\right)$ holds true iff

$w$ is an epistemic alternative for $\mathrm{A}$ in $w_{0}$ and

$w$ is a world where $q$ holds true under circumstances that A considers stereotypical.

11 Von Fintel \& Gillies (2010) argue in favour of analysing must as classical entailment.

12 The Tweety expectation is attested for normal agents A. Stereotypes may differ for penguin experts at the South Pole. Eventually each speaker decides what is stereotypical for her. 
Let us see how this plays out in the Tweety example. A knows 'Tweety is a bird' in $w_{0}$. The set $\lambda w$.STEREO(A, $w_{0}$,'Tweety is a bird', $w$ ) thus contains all worlds that are consistent with A's knowledge, and where 'Tweety is a bird' is true under circumstances compatible with A's expectations, including worlds where Tweety is a canary, a robin, a sparrow and so on. A's epistemic alternatives include worlds where Tweety is a penguin and cannot fly, but these are not in $\lambda w$.STEREO(A, $w_{0}$,'Tweety is a bird',w).

Stereotypes in my sense are individual stereotypes, not cultural stereotypes. Consequently, STEREO takes agent A as a parameter. Individual stereotypes allow us to account for the subjective nature of wohl declaratives, as we saw in (32a) ('measles'). Individual stereotypes also cover issues where there are no cultural stereotypes (like Hein's being or not being at sea). Given that different agents A and B can have different $q$-experiences, (34) holds true.

(34) For different agents A, B $\lambda w$.STEREO $\left(\mathrm{A}, w_{0}, q, w\right) \neq \lambda w$.STEREO $\left(\mathrm{B}, w_{0}, q, w\right)$ is possible.

The STEREO relation also contains parameter $q$, the relevant knowledge of agent A. When A in (17) asserts that Hein is at sea then A does not mean to say "in stereotypical worlds per se, Hein is at sea" but "in stereotypical worlds where Hein's house is locked and shutters closed, Hein is at sea". I leave it open whether stereotypical $q$-worlds are ordered, as such an ordering does not matter for the present analysis.

Let me review more facts about STEREO. According to the definition, stereotypical $q$-worlds are worlds where $q$ is true. Yet, the actual world need not be stereotypical for $q$.

$$
\begin{aligned}
& \forall w\left(\operatorname{STEREO}\left(\mathrm{A}, w_{0}, q, w\right) \rightarrow q(w)\right) \\
& \text { Possible: } \neg \operatorname{STEREO}\left(\mathrm{A}, w_{0}, q, w_{0}\right)
\end{aligned}
$$

Finally, different propositions $q$, $q$ ' can lead to different sets of stereotypical worlds $\lambda w$.STEREO(A, $\left.w_{0}, q, w\right), \lambda w$.STEREO $\left(\mathrm{A}, w_{0}, q^{\prime}, w\right)$. This holds in particular for propositions $q$ and $q \wedge r$, laying the basis for defeasible inference. We now turn to the definition of defeasible inference.

(36) Let $q, p$ be propositions. Assume that agent A in $w_{0}$ knows $q$. A can defeasibly infer $p$ from $q$ iff $\forall w$ (STEREO(A, $\left.w_{0}, q, w\right) \rightarrow p(w)$ ). "All epistemic alternatives of A where $q$ is true under circumstances that A considers stereotypical are also worlds where $p$ is true." 
Let us apply (36) to the Tweety example. Let $q_{1}=$ 'Tweety is a bird' and $p$ $=$ 'Tweety can fly'. Assume that agent A knows that $q_{1}$ is true. According to (33), $\lambda w$.STEREO $\left(\mathrm{A}, w_{0}, q_{1}, w\right)$ contains only worlds where Tweety is a bird under circumstances that A considers stereotypical. Assume that, among other things, A expects that Tweety can fly. Thus $\lambda w$.STEREO $\left(\mathrm{A}, w_{0}, q_{1}, w\right) \subset p$ and A can hence defeasibly infer from $q_{1}$ that $p=$ 'Tweety can fly'.

Assume that A gathers new information $q_{2}=$ 'Tweety is a penguin' and now knows $q_{1} \wedge q_{2}$. The stereotypical worlds $\lambda w$.STEREO $\left(\mathrm{A}, w_{0}, q_{1} \wedge q_{2}, w\right)$ are different from those for $q_{1}$. Among other things, $p=$ 'Tweety can fly' is false in these worlds. Based on new knowledge, A draws new inferences and discards former beliefs.

As a consequence of definition (36), classical inference is a limit case of defeasible inference. If $q \rightarrow p$ in terms of classical logic, then $q$ also defeasibly entails $p$. Likewise if A knows $p$, and $p$ is thus true in all epistemic alternatives of A, then A can defeasibly infer $p$ from any premiss. This will be relevant when we consider the pragmatics of conjectural questions in Section 4.

\subsubsection{Analysing wohl}

We can now define the lexical entry for wohl. Following M. Zimmermann (2008), I assume that wohl takes scope in the ForceP at LF; specifically above negation, conditionals and question formation. ${ }^{13}$ The utterance context $c$ supplies several parameters. First, wohl refers to the speaker $s p(c)$. Second, it provides a current issue $Q$ that the speaker has to settle, minimally whether $p^{14}$ Third, there is a maximal body of relevant knowledge of $s p(c)$ that pertains to the issue. This lays the ground for the (pre-final) lexical entry for wohl in (37).

(37) $\llbracket w o h l \rrbracket^{c, w_{0}}$ in utterance context $c$ and world $w_{0}$ contributes

a. Presuppositions:

(i) $c$ determines an issue $Q$ and $q(c)$, the maximal body of knowledge of $s p(c)$ relevant for $Q$.

(ii) $q$ must include witnessed facts.

\section{b. Denotation:}

$$
\llbracket w o h l \rrbracket^{c, w_{0}}=\lambda p . \forall w\left(\operatorname{STEREO}\left(s p(c), w_{0}, q(c), w\right) \rightarrow p(w)\right)
$$

13 Like earlier authors, I refrain from extending the data to clauses embedded under verba dicendi.

14 I refrain from using the term "question under discussion" QUD to stay away from phenomena that are orthogonal to the present case. 
Conjectural questions

\section{c. Updates:}

The utterance wohl $p$ asserts the at-issue content $p$.

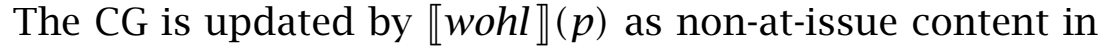
the sense of Murray 2014.

The presupposition provides the issue $Q$. In the absence of other issues I assume that $Q=$ whether $p$ ? by default. The relevant knowledge $q(c)$ comprises knowledge that could be useful to $Q$; it must include witnessed facts. The maximality clause (37ai) ensures that A isn't licensed to utter wohl $p$ and wohl not- $p$ at the same time. ${ }^{15}$ It states that when uttering wohl $p$, A does not currently know facts that defeat $p$. Let me illustrate (37) for example (7), uttered in a context $c$ and world $w_{0}$.

(38) Hein ist wohl auf See.

a. LF: [ForceP wohl [CP Hein ist auf See ] ]

b. $\llbracket$ Hein ist auf See $\rrbracket^{c}=\lambda w$.HEIN-AT-SEA $(w)$

c. $\llbracket[$ ForceP wohl $[\mathrm{CP}$ Hein ist auf See $]] \rrbracket^{c}$ $=\llbracket$ wohl $\rrbracket^{c}\left(\llbracket\right.$ Hein ist auf See $\left.\rrbracket^{c}\right)$

$=\lambda p \forall w\left(\operatorname{STEREO}\left(s p(c), w_{0}, q(c), w\right) \rightarrow p(w)\right)(\lambda w . \operatorname{HEIN-AT-SEA}(w))$

$=\forall w\left(\operatorname{STEREO}\left(s p(c), w_{0}, q(c), w\right) \rightarrow \operatorname{HEIN-AT-SEA}(w)\right)$

Asserted: $\lambda w$. HEIN-AT-SEA $(w)$

Non-at-issue content: $\forall w\left(\operatorname{STEREO}\left(s p(c), w_{0}, q(c), w\right) \rightarrow \operatorname{HEIN}-\operatorname{AT}-\operatorname{SEA}(w)\right)$

Assume a context c* where Maria utters (38) with issue $Q=$ Where is Hein? She knows $q=$ 'Hein's house is locked and shutters are closed'. Her utterance rests on $q$. (38) can thus be paraphrased as "given what I know (about issue $Q)$, I infer that Hein is at sea". Maria's utterance contributes the claim $p=$ 'Hein is at sea'. At the same time she adds at the non-at-issue level: "I have evidence $q$ that defeasibly entails $p$ ".

\subsection{Predictions}

The present section evaluates the predictions of the proposed analysis, starting with Faller's tests for wohl.

15 The notion of maximal body of relevant knowledge is similar to "indexical knowledge" as used in Hara's analysis of Japanese youda (Hara 2006). Youda, like wohl, is an inferential evidential. The notion used here is slightly more specific than Hara's in order to provide for defeasible inferences. 
Declarative wohl $p$ competes with the plain assertion $p$. The plain assertion lacks the hedge that $p$ is defeasibly inferred. The use of wohl $p$ thus gives rise to the scalar implicature that the speaker does not know $p$ for certain. This predicts the contrast in examples (7) and (8).

The implicature does not arise when the non-at-issue content is justified for other reasons. This offers an explanation for Göbel's paradox (9). In the given situation, the sentence da hab ich mich wohl geirrt ('I have been wrong I suppose') is uttered in a context where the addressee has just pointed out A's error. Speaker A conveys that he has (defeasibly) inferred $p$. This is relevant as A presents herself as capable of learning. Therefore the complex utterance wohl $p$ is justified and does not give rise to further scalar implicatures. ${ }^{16}$ Whenever the non-at-issue content of wohl $p$ is not justified as a relevant information about A's drawing inferences, the scalar implicature remains, as (22) confirmed for test (vii).

The present analysis predicts that declarative wohl $p$ is infelicitous if the speaker believes $p$ to be false. We predict that the speaker proposes a CG update by $p$, which is tantamount to asserting $p$. The speaker is committed to $p$ by the maxim of quality. Note that the maximality clause also ensures that A cannot propose contradicting prejacents for CG update. This is again in line with the data.

The observation that wohl scopes over negation and question formation is predicted in the same manner as in M. Zimmermann 2004, 2008. We adopt Zimmermann's assumption that wohl takes scope at the highest CP level at LF. It follows that the semantic contribution of wohl outscopes negation as well as question formation.

The assent/dissent tests showed that the prejacent $p$ is at-issue content, whereas the information that the speaker infers $p$ is not. We predict this by assuming that the speaker proposes a CG update with $p$ and at the same time, the proposition 'given what I know, I defeasibly infer that p' enters the CG by non-at-issue update (Murray 2014). The latter content can therefore not be targeted by expressions of assent or dissent. In this, wohl $p$ differs from probability or possibility statements about $p$.

We could capture the observation that wohl doesn't scope below conditionals as an island violation, following M. Zimmermann 2008. However, the division into at-issue and non-at-issue content allows for an interesting alternative explanation. Consider (19), repeated below.

16 For further examples see Göbel 2018, who assumes an explanation along the same lines. 
Conjectural questions

(39) Wenn Hein wohl auf See ist, dann kochen wir Spaghetti.

If Hein wohl at sea is, then cook we spaghetti

Factual conditional: 'Given that you assume/infer that Hein is at sea, we'll cook spaghetti.'

Allowing for wohl to take scope at the CP-level of the conditional clause, we predict a non-at-issue update of the CG by wohl('Hein is at sea'). We thus correctly predict that the speaker of (39) believes that Hein is at sea, i.e., utters a factual conditional.

The analysis so far does not account for the interrogative flip, to which we turn in Section 3. With a slight generalization of (37) we can account for standard wohl questions (Section 3 ) as well as verb-final wohl questions (Section 4).

We now turn to the specific differences between the ASSUME-based analysis and the one proposed here. The present account rests on the intuition that wohl $p$ presents the prejacent as a defeasible inference. Example (25) is analysed as follows (where I focus on the non-at-issue content added by wohl).

(40) A: Oma ist wohl einkaufen gegangen.

Granny is wohl shopping gone

is uttered in a context with issue $Q=$ Where is Granny?

A's relevant knowledge in $c: q=q_{0} \wedge \ldots \wedge q_{3}$

$q_{0}: \quad$ It is Friday afternoon.

$q_{1}$ : $\quad$ Granny often goes shopping on Friday afternoon.

$q_{2}$ : Her shopping bag and purse are missing.

$q_{3}: \quad$ Her slippers are in the hall.

We predict the following denotation for (40), uttered by speaker A in context c.

$\llbracket\left[\right.$ ForceP wohl [CP Oma ist einkaufen gegangen ] ] $\rrbracket^{c, w_{0}}$

$=\lambda p \forall w\left(\operatorname{STEREO}\left(\mathrm{A}, w_{0}, q(c), w\right) \rightarrow p(w)\right)(\lambda w$. WENT-SHOPPING(GRANNY, $\left.w)\right)$

$=\forall w\left(\operatorname{STEREO}\left(\mathrm{A}, w_{0}, q(c), w\right) \rightarrow\right.$ WENT-SHOPPING $($ GRANNY, $\left.w)\right)$

Assertion: $\lambda w$.WENT-SHOPPING(GRANNY. $w$ )

Non-at-issue content:

$\lambda w_{0} . \forall w\left(\right.$ STEREO $\left(\mathrm{A}, w_{0}, q(c), w\right) \rightarrow$ WENT-SHOPPING(GRANNY, $\left.\left.w\right)\right)$

The non-at-issue content is true in $w_{0}$ iff all worlds that A considers stereotypical for $q_{0}-q_{3}$ are worlds where Granny went shopping. Hence if the world is stereotypical for $q$, Granny went shopping. 
The addressee can ask for A's evidence, why do you think so?. A indicates that $p$ is defeasibly inferred from $q$. B inquires into the tacit premise $q$ of the inference. We can also explain how short questions why? can ask for two levels of reasons. In (40), B could ask about the reasons for Granny to go shopping, or else for the reasons $q$ to infer that Granny went shopping. A detailed analysis is left for the future.

Finally, the analysis captures the subjective nature of wohl inferences. Whether or not speaker A is inclined to utter wohl $p$ depends on two factors. First, the content of wohl $p$ depends on A's body of relevant knowledge $q$ pertaining to the issue whether $p$. What A knows can differ from what B knows and therefore A can be in a position to utter wohl $p$ when B is not. Second, the set $\lambda w$.STEREO(A, $\left.w_{0}, p, w\right)$ reflects A's personal experience with $q$-worlds. It can differ from B's stereotypical $q$-worlds $\lambda w$.STEREO $\left(\mathrm{B}, w_{0}, p, w\right)$. This accounts for the difference between defeasible inference from scientific theory and subjective opinion that we saw in (32) measles.

Let me lastly turn to the observation that wohl $p$ cannot express that $p$ is statistically likely, as shown in example (23). So far, this doesn't strictly follow from the analysis but offers further insights into what speakers of German consider stereotypical courses of events. In the example, the speaker saw a container with one black and nine white marbles. This is a witnessed fact as other witnessed facts ('Granny's slippers in the hall', 'Hein's house locked'), and translates into a 90\% chance to draw a white marble. But is being likely the same as being a stereotypical outcome?

The data suggest that this is not the case. Speakers seem to reason as follows: Thinking about worlds where A draws a marble, stereotypical worlds for 'A drew a marble' include worlds where the marble is white (the majority outcome) as well as worlds where the marble is black (the minority outcome). One type of outcome may be statistically less likely than the other, but nothing in the unlikely outcome violates our normal manipulation of marbles or the normal physical movement of objects in containers. ${ }^{17}$ Therefore the stereotypical 'A draws a marble' worlds include both types of outcome whence A is not justified to utter Ich habe wohl eine weiße Murmel gezogen.

17 German informants generally agree with surprising consistency that wohl is not licensed in the marble scenario. It may be worth pointing out, however, that individual speakers and in particular expert statisticians are able to take probably $p$ as weak evidence in favour of $p$ and thus accept wohl $p$ in this case. 
Conjectural questions

\section{Evidential wohl in standard questions}

This section extends the analysis of wohl to standard questions with the interrogative flip, as in example (2) repeated below.

(20) Wo ist Hein wohl?

Where is Hein wohl

'What do you think: where might Hein be?'

While evidential markers in many languages show the flip reading in questions, counterexamples have been reported and it would therefore be mistaken to derive the flip reading on basis of general pragmatic principles. $\mathrm{M}$. Zimmermann's (2008) feature-based analysis successfully captures the binary distinction by features decl and int. Yet, an extension to CQs would require additional features and thus conflict with the aim to integrate German in the typological landscape of conjectural questions.

I propose Lim's analysis of Korean evidential -te (Lim 2010, 2011, Lim \& Lee 2012) which rests on a elegantly simple idea: Evidentials are context dependent, as they refer to the epistemic background of the speaker $s p(c)$ in $c$. This context dependence is captured in terms of Kaplan's (1989) character theory. According to Kaplan, sentences denote characters, functions from contexts to propositions, which capture the meaning of indexical expressions (T. E. Zimmermann 2012, Schlenker 2018). While questions normally denote sets of propositions, questions with evidentials instead denote sets of characters. Each answer contains the evidential, which is taken into account in future answering contexts. As the addressee of the question will be the speaker of the answer, this models the evidential flip.

In order to apply Lim's idea, we have to adjust the lexical entry of wohl as in (41). Wohl takes scope over the remaining clause $S$ and combines with the denotation $\llbracket S \rrbracket^{c^{*}}$ in utterance context $c^{*}$.

(41) Meaning of 'wohl' (final version):

$\llbracket w o h l \rrbracket^{c, w_{0}}$ in utterance context $c$ and world $w_{0}$ contributes ...

a. Presuppositions:

(i) $c$ determines an issue $Q$ and $q(c)$, the maximal body of knowledge of $s p(c)$ relevant for $Q$.

(ii) $q$ must include witnessed facts.

b. Denotation:

$\llbracket w o h l \rrbracket^{c^{*}, w_{0}}=\lambda p \lambda c \lambda w_{0} . \forall w\left(\operatorname{STEREO}\left(s p(c), w_{0}, q(c), w\right) \rightarrow p(w)\right)$ 
'Given prejacent $p$ and context $c$, the speaker $s p(c)$ asserts that given her relevant knowledge $q(c)$ with respect to the issue $Q$ in $c$, all worlds where $q$ is true under stereotypical circumstances are worlds where $p$ holds true.'

\section{c. Updates:}

The utterance wohl $p$ asserts the at-issue content $p$.

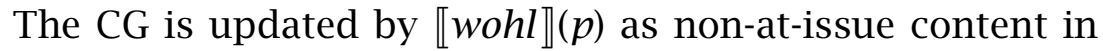
the sense of Murray 2014.

The contribution of wohl in assertions is the same as in the earlier version (37), as the derivation in (42) illustrates.

(42) Hein ist wohl auf See.

a. LF: [ForceP wohl [CP Hein ist auf See ] ]

b. $\quad$ Hein ist auf See $\rrbracket^{c^{*}}=\lambda w$.HEIN-AT-SEA $(w)$

c. $\quad$ wohl $[$ Hein ist auf See $] \rrbracket^{c^{*}}$

$=\llbracket$ wohl $\rrbracket^{c^{*}}(\llbracket$ Hein ist auf See $\left.) \rrbracket^{c^{*}}\right)$

$=\lambda p \lambda c \lambda w_{0} . \forall w\left(\operatorname{STEREO}\left(s p(c), w_{0}, q(c), w\right) \rightarrow p(w)\right)$

$(\lambda w$.HEIN-AT-SEA $(w))$

$=\lambda c \lambda w_{0} \cdot \forall w\left(\operatorname{STEREO}\left(s p(c), w_{0}, q(c), w\right) \rightarrow \operatorname{HEIN}-\operatorname{AT}-\operatorname{SEA}(w)\right)$

The sentence denotes a character that can be paraphrased as "Given context $c$, the stereotypical worlds of $s p(c)$ plus the speaker's knowledge $p(c)$ about the given issue entail that Hein is at sea”. Following Lim, the $c$ argument in assertions is instantiated by the utterance context. Let us assume that Maria utters $(42)$ in context $c^{*}$, relying on knowledge $q\left(c^{*}\right)=$ 'Hein's duffel bag is missing'. (42) in $c^{*}$ thus conveys the following.

(43) $\lambda w_{0} . \forall w\left(\right.$ STEREO (Maria, $w_{0}$, 'duffel bag missing', $\left.w\right) \rightarrow \operatorname{HEIN-AT-SEA}(w)$ ) 'All stereotypical worlds where Maria's relevant knowledge is true (namely, Hein's duffel bag is missing) are worlds where Hein is at Sea.'

Maria proposes a CG update by Hein is at sea and conveys non-at-issue that she knows something that allows her to infer Hein is at sea.

While the two semantic entries for wohl make identical predictions for assertions, only (41) can account for the interrogative flip. We adopt a Hamblin semantics for questions, where $Q$ denotes the set of propositions that 
Conjectural questions

are answers of $Q^{18}$ Wohl scopes over question operators and thus combines with the denotation of $Q .{ }^{19}$ Following Lim, I assume pointwise semantic composition, indicated by + . We thus derive a set of characters for the question wohl $Q$, which is illustrated in (44) for the question 'where is Hein?'. I assume the possible answers 'Hein is at Sea', 'Hein is on Hawaii' and 'Hein is at home'.

(44) Wo ist Hein wohl?

Where is Hein wohl

'where, do you think, is Hein?'

a. wo ist Hein? c $^{*}$

$=\{\lambda w \cdot \operatorname{HEIN-AT-SEA}(w), \lambda w \cdot \operatorname{HEIN-ON-HAWAII}(w)$,

$\lambda w \cdot \operatorname{HEIN-AT-HOME}(w)\}$

b. $\llbracket$ wohl $[$ wo ist Hein] $] \rrbracket^{c^{*}}$

$$
\begin{aligned}
= & \llbracket w o h l \rrbracket^{c^{*}}+\llbracket \text { wo ist Hein } \rrbracket^{c^{*}} \\
= & \left\{\lambda c \lambda w_{0} . \forall w\left(\operatorname{STEREO}\left(s p(c), w_{0}, q(c), w\right) \rightarrow \operatorname{HEIN-AT-SEA}(w)\right),\right. \\
& \lambda c \lambda w_{0} . \forall w\left(\operatorname{STEREO}\left(\operatorname{sp}(c), w_{0}, q(c), w\right) \rightarrow \operatorname{HEIN-ON-HAWAII}(w)\right), \\
& \left.\lambda c \lambda w_{0} . \forall w\left(\operatorname{STEREO}\left(\operatorname{sp}(c), w_{0}, q(c), w\right) \rightarrow \operatorname{HEIN-AT-HOME}(w)\right)\right\}
\end{aligned}
$$

The question denotes a set of characters that can be paraphrased as "The speaker in $c$ defeasibly infers from what s/he knows in $c$ that $p$ ". The addressee of the question is thus offered a choice of utterances in response to (44). Whichever she chooses will hedge the answer with wohl. Assume that Tom asks (44) to Maria in $c$. The context parameter in the set of answers will be instantiated by a context $c^{*}$ where Maria provides an answer. Whichever of the proposed utterances, it rests on Maria's relevant knowledge about $Q$ and Maria's stereotypes. We thus predict the interrogative flip in questions. ${ }^{20}$

While the interrogative flip is intuitively a natural way to make sense of an evidential in a question, the reading is not universally available. San Roque, Floyd \& Norcliffe (2017) report on languages where evidentials are prohibited in questions (e.g., Samoyedic languages in Künnap 2002: p. 149, Aikhenvald

18 The analysis is compatible with Groenendijk \& Stokhof 1984 but I want to keep matters simple at this point. The present account is more conservative than Farkas 2017, 2020, Roelofsen \& Farkas 2017, Hara 2018 which implement conjectural questions in inquisitive semantics.

19 Apart from the data in M. Zimmermann 2008, see also Lim 2011 for type-logical reasons.

20 The account leaves open the possibility that speakers answer the questions without using wohl, in particular if they know the answer for certain. I assume that this is licensed by general cooperativity principles that always allow the speaker to offer more information than requested. The principle also underlies indirect questioning acts, as well as answers to self-addressed questions. 
2004a: p. 11). In Eastern Pomo, evidentials in questions are anchored to the speaker (San Roque, Floyd \& Norcliffe 2017). Finally, a broad range of nonrelated languages do not exhibit the interrogative flip and instead use evidentials to mark conjectural questions. These include Ecuador Quechua (San Roque, Floyd \& Norcliffe 2017), Gitksan, St'át'imcets and Nełe?kepmxcín (Littell, Matthewson \& Peterson 2010), Cuzco Quechua (Faller 2002), Cheyenne (Murray 2010a,b, 2016)), Tariana (Aikhenvald 2003), Shipibo-Konibo (Valenzuela 2003), Japanese (Hara 2006, 2018) and Italian (Mari 2010, Eckardt \& Beltrama 2019).

Given the variety of patterns, it is appropriate that our analysis correctly links the flip reading to specific lexical properties of individual evidentials. ${ }^{21}$ German wohl is special in that it contributes both to the flip reading and to conjectural questions. These show nonstandard verb-final syntax as a further cue. We now turn to the core part of the paper, verb-final wohl questions in German and their interpretation as conjectural questions.

\section{Verb-final wohl questions in German}

Verb-final wohl questions in German like (45) differ from standard questions in that they share the syntax of subordinate clauses with the verb in sentencefinal position. These questions have been studied as self-addressed questions (Altmann 1987, Truckenbrodt 2006, 2013, Lohnstein 2007), illustrated by examples like the following Truckenbrodt 2006: p. 274 .

(45) (A: I haven't had any news about Peter in a long time.

B: Me neither.)

A: Ob er wohl immer noch kubanische Zigarren mag?

whether he wohl still Cuban cigars likes

'I wonder whether he still likes Cuban cigars.'

Questions like (45) can however be uttered in the presence of an interlocutor and even with a clear communicative intention (Plunze \& Zimmermann 2006). This is problematic for definitions of CQs that are based on the absence of an interlocutor (Jang 1999, Jang \& Kim 1998, Miyagawa 2012). ${ }^{22}$ We must hence find further criteria to characterize CQs.

21 For a survey of other flip accounts, see Lim 2011 which discusses Faller 2002, Garrett 2001 and Murray 2010a, comparing their accounts for interrogative flip to the present analysis. I refer the reader to his arguments.

22 Eckardt \& Disselkamp (2019) show that self-addressed questions in Korean are likewise possible in the presence of an interlocutor, pace Jang 1999. 
Conjectural questions

Section 4.1 explores the pragmatic profile of verb-final wohl questions and compares them to standard wohl questions and standard questions in German. Verb-final wohl question are typically used in contexts where

a. the speaker does not expect the addressee to know the answer.

b. the speaker does not request an answer.

c. the addressee can remain silent without violating the rules of discourse.

d. the speaker invites the addressee to speculative discourse about the topic.

Standard questions and standard wohl questions show a different profile, as will be detailed in 4.1. While standard questions can also used in CQ contexts, specifically in situations where the speaker is alone, such uses are atypical, whereas they are the only possible ones for verb-final wohl-questions. The pragmatic profile extends to CQs in other languages (see Section 5). Section 4.2 details an analysis for verb-final wohl-questions. Section $4.3 \mathrm{com}$ pares the present proposal to earlier analyses of verb-final questions in German and CQs in other languages.

\subsection{Data}

The present section delineates the pragmatic differences between standard questions (46), standard wohl questions (47) and verb-final wohl questions (48).

(46) Wo ist der Schlüssel? where is the key

'Where is the key?'

(47) Wo ist wohl der Schlüssel? where is wohl the key

'Where, do you think, is the key?'

(48) Wo wohl der Schlüssel ist? where wohl the key is

'Where might the key be, I wonder.' 
In uttering questions like (46), the speaker requests the addressee to provide an answer (Searle 1969). The speaker wants to gain information and believes that the addressee can provide it. Posing a standard question only makes sense if the speaker expects that the addressee knows the answer. ${ }^{23}$

Standard wohl questions like (47) request the addressee to conjecture an answer that is true in their relevant stereotypical worlds. They are typically posed if the speaker wants to gain information and believes that the addressee does not know but may be able to guess an answer. Allowing for answers that rest on defeasible inference instead of knowledge, the speaker makes it easier for the addressee to fulfill the request.

The utterance of a verb-final wohl questions (48) doesn't constitute a request. These are typically posed if the speaker wants to know the answer but believes that the addressee doesn't know more about the issue than herself. Getting an answer is not of importance for the speaker's immediate tasks. The addressee is invited to react in some way (Plunze \& Zimmermann 2006), for instance by engaging in joint speculations about the topic.

The following scenarios offer contexts of use for the standard question (46), the standard wohl question (47) and the verb-final wohl question (48).

(I) Standard question: A will empty B's mailbox while B is on holiday. Receiving instructions, A realizes that the mailbox has a lock. A asks B: (46)

A's question is a request for an answer. A expects that B knows the answer, and knowing the answer is necessary for A's job of taking care of B's mail.

(II) Standard wohl: A and B are Airbnb guests. They decide to take care of their absent host's mail. A realizes that the mailbox is locked. A asks B: (47)

A requests B to guess an answer to (47). A knows that B doesn't know more about the key than herself, but hopes for smart conjectures. Getting an answer is necessary for A's task, taking care of the mail.

(III) Verb-final wohl: Walking on the beach, $A$ and B find a wooden box sealed with a huge lock. Taking interest in the object, $A$ asks B: (48)

A knows that B doesn't know the answer. A does not request B to provide an answer. Knowing the answer is not of immediate importance for A's aims. It would be natural for B to start speculating with A about the question.

23 We leave aside non-cooperative use of questions, rhetorical questions, theme-setting questions, etc. 
Conjectural questions

The difference between Scenarios II and III is subtle. In either situation, B cannot be expected to know the answer. In scenario II the speaker is pursuing a task that requires an answer to where is the key?. In scenario III the speaker is interested in the question just for curiosity's sake. The following minimal pair highlights a further difference between wohl questions in standard and verb-final syntax.

(49) Standard question wohl: B is a member of a job search committee. Candidates have been interviewed, but the final decision remains to be made in the next meeting. A asks B:

A: Wer bekommt wohl den Job?

who gets wohl the job

'Who, do you think, will get the position?'

(50) Verb-final wohl: The job committee is meeting behind closed doors. $A$ and $B$ are waiting outside for the decision to be announced. Neither of them has insider knowledge. A asks B:

A: Wer wohl den Job bekommt?

who wohl the job gets

'I wonder who will get the job.'

Example (49) confirms that standard wohl questions require answers. ${ }^{24} \mathrm{~B}$ has privileged knowledge and A hopes to elicit an informed conjecture. In (50), A does not assume that B knows more about the question than herself. A expresses curiosity but doesn't request an answer from B. B is invited to engage with A in joint speculation.

A final set of examples illustrates the differences in exam like situations. In each situation, an adult A and a child B are looking at a picture book. In (51) and (52), the adult knows the answer and wants to know whether B can also answer the question. Different question types are appropriate in different scenarios and pose different requests.

(51) Standard: The picture shows a king, a princess, a knight and a horse. $B$ is very little and $A$ invites $B$ to identify the characters.

A: Wo ist die Prinzessin?

where is the princess

'Where is the princess?'

24 This corrects Thurmairs claim that "in uttering w-questions with wohl the speaker always asks herself as well as the interlocutor" (Thurmair 1989: p. 144). 
(52) Standard wohl: $B$ is an older child and can do picture puzzles. The picture shows a bush behind which the crown of the princess peeps out.

A: Wo ist wohl die Prinzessin? where is wohl the princess

'Where, do you think, is the princess?'

(53) Verb-final wohl: Again, B is an older child. The final picture of the story shows the princess' room deserted: The princess has left.

A: Wo wohl die Prinzessin ist?

where wohl the princess is

'Where might the princess be, I wonder.'

The standard question in (51) is appropriate as A wants to see whether B can name characters and thus answer the question. A conveys that B should be able to answer the question without much thinking. In (52), the standard wohl question is appropriate, as A wants to convey that defeasible inferencing can be part of finding an answer. The verb-final wohl question in (53) can be posed even though there is no "true" answer in this scenario at all. Answering (53) is tantamount to inventing a story about the princess. The question is not a request for information but an invitation to speculate.

The following attested example further illustrates the function of verbfinal wohl questions as starters of conjectural discourse. ${ }^{25}$

(54) (A and B, in coffee bar, observe a lonely stranded mattress leaning at the house next door.)

A: Wer die wohl da hingestellt hat?

Who that.one wohl there put has

'Who may have left that one there, I wonder.'

In the reported situation, A did not assume that B knew or could guess the answer. The utterance was intended as a starter of a conversation on the nature of stranded mattresses in general. Similar discourse aims for CQs were reported for Shipibo-Konibo (Valenzuela 2003), Gitksan (Peterson p.c.) and Italian (Zucchi, p.c.). Finally, if the addressee happens to know the answer $\mathrm{s} /$ he can assert it. The particle wohl will not occur in the answer.

The scenarios list ideal question-situation pairs. Other pairings may happen, but the speaker's choice of question indicates how she conceives the 25 Gisela Disselkamp, p.c. 
Conjectural questions

utterance situation to be. ${ }^{26}$ For instance, asking a standard wohl question in (53) would invite the child to guess the answer, suggesting that there is yet a true answer in some sense. A verb-final wohl question in (52) would indicate that A will share conjectures with B in their joint search for the princess. The data corroborate our initial choice of the term conjectural questions for German verb-final wohl questions.

Before turning to the analysis, let me briefly review other possible grammatical cues of CQs in German. Earlier authors on German CQs assume that any question in German can be turned into a CQ by verb-final syntax (Lohnstein 2000, Truckenbrodt 2013, 2006, Oppenrieder 1989). This is mistaken, as the use of evidential wohl is mandatory in constituent CQs. (55) cannot express a conjectural question.

(55) *Wo der Schlüssel ist?

where the key is

Unavailable: 'Where might the key be, I wonder.'

Mandatory wohl in constituent CQs also offers a strong argument against an analysis of CQs in terms of ellipsis. At first sight, it could be tempting to assume a tacit embedding clause like "Ich frage mich, wo ..." ('I ask myself where ...'). Yet, the particle wohl isn't mandatory in questions embedded under rogatory verbs. If verb-final questions were elliptical, we would expect that every overt embedded question has a CQ counterpart. Given that Ich frage mich, wo der Schlüssel ist ('I ask myself where the key is') is perfectly grammatical, (55) should be an acceptable CQ which in fact it is not. ${ }^{27}$

A further way to express CQs are verb-final questions with modal mag. These can lack wohl, as illustrated in (56).

(56) Wo der Schlüssel sein mag?

where the key be may

'Where may the key be, I wonder.'

German mag is cognate to English may, might but is no longer in use as a possibility modal in contemporary German. While the parallel between mag-

26 Additional instructions extend the appropriate uses of standard questions. A could utter the German equivalent to: Give me a guess: where is the princess? thus using a standard question to elicit the kind of answer that is appropriate for standard wohl questions. I will not go into these data.

27 See Truckenbrodt 2013, M. Zimmermann 2011 for further arguments in favour of a root clause analysis. 
questions and wohl-questions is tempting, I leave this variety unexplored for now.

Polar questions pose a special case in that they allow conjectural interpretations without wohl.

(57) Ob der Schlüssel im Auto ist?

if the key in.the car is

'I wonder whether the key is in the car.'

While this could lend support to the claim that verb-final syntax triggers CQ readings, some native speakers find CQs like (57) marked at the beginning of discourse (Gutzmann 2011). ${ }^{28}$ Informants however agree that polar verbfinal questions with wohl are acceptable without any contextual restrictions. This suggests that polar verb-final questions with wohl should be viewed as the normal case. In this, I deviate from earlier authors who take (57) to be the standard case of German conjectural questions and posit that verbfinal syntax alone suffices to trigger conjectural readings (Oppenrieder 1989, Lohnstein 2000, 2007, Truckenbrodt 2006, M. Zimmermann 2013).

Finally, verb-final CQs can include the particle bloß ('only') which turns them into an extreme ignorance question (Obenauer 2004, den Dikken \& Giannakidou 2002, Rawlins 2009, Eckardt \& Yu 2020).

(58) Wo bloß der Schlüssel ist!? where only the key is 'where on earth may the key be (I wonder).'

The contribution of bloß to standard and verb-final questions is worth a study in its own right but I leave it aside here.

\subsection{Analysis}

The analysis of verb-final wohl questions in German should predict the following facts: It must predict that the addressee is not requested to answer and that the question can be an invitation to joint speculation. Moreover, it must explain why evidential wohl is mandatory and should offer a basis to understand why evidential markers serve as cues for conjectural questions in many languages.

28 Acceptance is facilitated in situations where the polar question is interpreted as a guess ('the key is in the car') rather than a question (Oppenrieder 1989). The restrictions on licensing contexts are however unclear and speakers report shifting intuitions. 
Conjectural questions

I will elaborate the idea that verb-final wohl questions denote answers that are defeasibly inferred from pooled knowledge of speaker and addressee. They are asked in the spirit of "let us jointly conjecture an answer". To achieve this, I propose that wohl is oriented to speaker and addressee $\mathrm{A} \oplus \mathrm{B}$ as a plurality (Link 1983). Verb-final wohl questions can be paraphrased as "which answers do we get if we pool knowledge and draw defeasible inferences?" As defeasible inferences are not conservative, B cannot start inferring from his private knowledge because A might know facts that defeat B's inferences.

The formalization rests on a silent operator SHARE that serves two purposes. In syntax, SHARE blocks movement of the verb to $\mathrm{C}^{0}$ and thus ensures verb-final syntax. Semantically, the operator instantiates the sentient agent of wohl with $s p(c) \oplus a d(c)$, the plurality of speaker and addressee in the utterance context. Section 4.2.1 presents the analysis for constituent verb-final questions and 4.2.2 extends the account to polar verb-final questions. The analysis is tailored for German where CQs are marked by two cues: wohl and verb-final syntax. Section 5 discusses how the pragmatic ingredients of the present account can be recombined to account for evidentials as CQ markers in other languages.

\subsubsection{Constituent verb-final wohl questions}

I follow Bayer \& Obenauer's (2011) analysis for German root clauses where $\mathrm{CP}$ and ForceP are identified. In standard main clauses, the verb is fronted to $\mathrm{C}^{0}$, yielding $\mathrm{V} 2$ syntax (in declaratives) or $\mathrm{V}_{1}$ syntax (in questions and imperatives). Open or silent elements in $\mathrm{C}^{0}$ block verb-movement and thus force the verb to stay in clause-final position.

I propose that the syntax and pragmatics of verb-final constituent questions is determined by a silent operator SHAREwhich is situated in $\mathrm{C}^{0}$ of questions and must be licensed by the presence of a wh-feature. The $w h$ constituent is fronted to SpecC like in standard questions, but SHARE in $\mathrm{C}^{0}$ prevents the verb from moving to second position and thus forces verb-final syntax. At LF, SHARE takes highest scope over the remaining clause, including wohl. SHARE is restricted to questions with wohl for reasons of logical type, as will become clear when we turn to the meaning of SHARE. ${ }^{29}$ In pragmatics, SHARE effects a context shift, defined in (59). The function ** maps context $c$

29 SHARE is restricted to questions by stipulation as I see no convincing evidence in German or other languages I know of that would justify its application in declaratives. I thank reviewers 
to $c^{* *}$ where $s p(c)$ and $a d(c)$ are jointly responsible for answering the question $Q$.

(59) For context $c$ and question at issue $Q$ in $c$, let $c^{* * *}$ be the context with:

$\operatorname{sp}\left(c^{* *}\right)=\operatorname{sp}(c) \oplus \operatorname{ad}(c)$,

$q\left(c^{* *}\right)=q_{s p(c)} \wedge q_{a d(c)}$,

where:

$q_{s p(c)}=d_{\text {def }}$ the maximal relevant knowledge of $s p(c)$ about $Q$ in $c$,

$q_{a d(c)}={ }_{\text {def }}$ the maximal relevant knowledge of $\operatorname{ad}(c)$ about $Q$ in $c$.

All other context parameters of $c^{* * *}$ as in $c$.

The context $c^{* *}$ is thus like $c$ with speaker and addressee as joint speakers. ${ }^{30}$ (59) extends our earlier notion of context in that it includes the maximal relevant knowledge of the addressee about $Q$. We can now define the denotation of SHARE.

$$
\llbracket \mathrm{SHARE} \rrbracket^{c}=c^{* *}
$$

SHARE makes context $c^{* *}$ available for its sister constituent. The operator is syntactically restricted to questions, and only shows pragmatic effect if the question denotes a set of characters (rather than a set of propositions). Section 3 argued that German questions with evidential wohl denote sets of characters. The context $c^{* *}$ combines pointwise with the set of characters. As before, I use + to indicate this in the derivation. ${ }^{31}$ We predict that SHARE is only felicitous if wohl is part of the sister clause and the sister clause is a question. The operator is predicted to be restricted to questions with wohl. Let us apply the analysis to (61).

$$
\begin{aligned}
& \text { Wo Hein wohl ist? } \\
& \text { where Hein wohl is } \\
& \text { 'Where might Hein be, I wonder.' }
\end{aligned}
$$

The syntax of (61) is as in (61a). The presence of SHARE blocks movement of the verb to $\mathrm{C}^{0}$.

for drawing attention to the potential combination of SHARE and declaratives but leave further exploration for the future.

30 Similar contexts with plural speakers were proposed by von Fintel \& Gillies (2011) to analyse the epistemic modal might.

31 It is still open whether other indexicals in questions give rise to sets of characters, and whether SHARE combines with them. Evidence would be indexicals that only allow for flipped interpretation in questions. 
Conjectural questions

a. [CP [SpecC Wo $\left._{1}\right]\left[\mathrm{C}^{\prime}\right.$ SHARE [IP Hein wohl t $t_{1}$ ist ] ] ]

At LF wohl c-commands the remaining clause. SHARE takes highest scope and is interpreted last. ${ }^{32}$ In the first step, we compute the ordinary question meaning of wo ist Hein? ('where is Hein?').

b. $\quad$ Wo Hein ist? $\rrbracket^{c}$

$$
=\{\lambda w \cdot \operatorname{HEIN-AT-SEA}(\mathrm{w}), \lambda w \cdot \operatorname{HEIN-ON-HAWAII}(\mathrm{w}),
$$

$\lambda w \cdot \operatorname{HEIN-AT-HOME}(w)\}$

The next step combines wohl with the question meaning. Applying (41) in Section 3, we derive the following set of characters.

$$
\begin{aligned}
& \text { c. } \llbracket \text { wohl [wo Hein ist?] } \rrbracket^{c} \\
& =\left\{\lambda c \lambda w_{0} . \forall w\left(\operatorname{STEREO}\left(s p(c), w_{0}, q(c), w\right) \rightarrow \operatorname{HEIN-AT-SEA}(w)\right)\right. \text {, } \\
& \lambda c \lambda w_{0} . \forall w\left(\operatorname{STEREO}\left(s p(c), w_{0}, q(c), w\right) \rightarrow \operatorname{HEIN-ON-HAWAII}(w)\right) \text {, } \\
& \left.\lambda c \lambda w_{0} . \forall w\left(\operatorname{STEREO}\left(s p(c), w_{0}, q(c), w\right) \rightarrow \operatorname{HEIN-AT-HOME}(w)\right)\right\}
\end{aligned}
$$

In the last step, the set of characters combines with context $c^{* *}$. As a result, we derive answers to $Q$ that are supported by joint defeasible inference by $\mathrm{A} \oplus \mathrm{B}$ together.

$$
\begin{aligned}
& \text { d. } \llbracket \text { SHARE[wohl [wo Hein ist?] }] \rrbracket^{c} \\
& =\llbracket \text { SHARE } \rrbracket^{c}+\llbracket \text { wohl }[\text { wo Hein ist? }] \rrbracket^{c} \\
& =\left\{\lambda w_{0} . \forall w\left(\operatorname{STEREO}\left(\operatorname{sp}(c) \oplus a d(c), w_{0}, q_{s p(c)} \wedge q_{a d(c)}, w\right)\right.\right. \\
& \rightarrow \operatorname{HEIN-AT-SEA}(w)) \text {, } \\
& \lambda w_{0} . \forall w\left(\operatorname{STEREO}\left(s p(c) \oplus a d(c), w_{0}, q_{s p(c)} \wedge q_{a d(c)}, w\right)\right. \\
& \rightarrow \operatorname{HEIN-ON-HAWAII}(w)) \text {, } \\
& \lambda w_{0} . \forall w\left(\operatorname{STEREO}\left(s p(c) \oplus a d(c), w_{0}, q_{s p(c)} \wedge q_{a d(c)}, w\right)\right. \\
& \rightarrow \operatorname{HEIN-AT-HOME}(w))\}
\end{aligned}
$$

What does it mean for $\mathrm{A} \oplus \mathrm{B}$ to draw a joint defeasible inference? Section 2.2.3 argued that defeasible claims rest on the speaker's maximal body of knowledge pertaining to question $Q$ at issue. The declarative Hein ist wohl auf See can be paraphrased as "considering all I know about $Q=$ 'where is Hein?' I defeasibly infer that he is at sea". The maximality condition predicts that A's assertion is not defeated by further facts known to A. Section 3 adopts the same maximality condition: When $\mathrm{B}$ answers question $Q=$ Wo ist Hein wohl? ('where is Hein wohl?') she must take into account her maximal body of knowledge that pertains to $Q$.

32 Alternative orders of composition would clash for type reasons. 
When $\mathrm{A} \oplus \mathrm{B}$ together draw defeasible inferences on issue $Q$ they must adhere to the maximality condition together. Before A proposes an inference $p$, she must ensure that B doesn't know something that defeats $p$. Similarly if B proposes an inference. A and B must base their inference on the maximal body of knowledge available to them as a group. They have to pool their relevant knowledge or else they run the risk of drawing conflicting inferences. ${ }^{33}$

What is, then, a rational reaction to question (61)? In normal situations, neither A nor B alone knows $q_{s p(c)} \wedge q_{a d(c)}$ and hence, neither A nor B is authorized to assert a proposition in (61d). Joint speculation is in fact one rational reaction to verb-final wohl questions. Ideally when A raises question (61), B should contribute her relevant knowledge, wait for A to contribute and before jointly making conjectures. In actual practice, however, speculations take a more open course where B immediately makes a conjecture, the interlocutors exchange relevant premises, A conjectures etc. until the issue is settled or dropped.

A second type of reaction is motivated by Searle's felicity conditions of questions and requests (Searle 1969: p. 66), which include the felicity condition that A must believe that B can give the answer to $Q$. In uttering a verbfinal wohl question, the speaker A implicates that she believes that B neither knows nor can conjecture the answer. (Otherwise, A would have uttered a standard question or a standard wohl question). Given this, B is justified to infer that A does not request her do to anything - and will remain silent (but see special scenarios below). ${ }^{34}$ The case is comparable to conventionalized indirect speech acts like can you pass the salt? Under normal circumstances, this question violates the Maxim of Relevance. To make sense of it, we infer that the speaker requests the salt. The conventional character of the request is evidenced by the fact that very similar questions (Are you able to pass me the salt? can not be used felicitously as requests for salt. In a similar vein, verb-final wohl questions are interpreted as expressions of interest to which silence is a conventional reaction. ${ }^{35}$

33 This is not the same as inferences based on CG knowledge. While CG comes about by intersection, pooled knowledge means forming the union of (limited parts of) A's and B's knowledge.

34 This should not be mistaken to predict that unanswerable questions never require answers. $Q$ is not unanswerable by content, but by form: The speaker chose a particularly complex form instead of simply asking a standard question.

35 Compare silence as conventional means to accept a claim (Farkas \& Bruce 2010). Interestingly, Littell, Matthewson \& Peterson (2010) argue along the same lines why conjectural questions remain unanswered. 
Conjectural questions

The conventional nature of silence as a reaction is confirmed when we look at special utterance situations. Take example (62) where A immediately shares her knowledge that pertains to question $Q$.

(62) A: I've just seen Hein carrying a torch, a bucket and a shovel.

Was Hein wohl vorhat?

What Hein wohl plans

'I wonder what Hein is up to.'

Assume that B (but not A) knows that these three things allow Hein to hunt for worms, necessary baits for fishing. Thus B can conjecture an answer and A cannot. Is B obliged to answer? According to my intuition, remaining silent is still an acceptable reaction to (62). This justifies the assumption that not answering is a conventionalized possible move for $\mathrm{B}$, not one that is forced by pragmatic processes.

A second special case arises when B knows the answer to the verb-final wohl question. Assume that, in (61), $p=$ 'Hein is on Hawaii' and B knows this. The logic of defeasible inference thus predicts that $B$ is authorized to answer: As B knows $p$, the epistemic alternatives of B are included in $p$. According to our analysis B's stereotypical $r$-worlds are a subset of B's epistemic alternatives for any $r$. Thus for any further evidence $r$ that $\mathrm{A} \oplus \mathrm{B}$ may take into account, the inference that $p$ remains valid. We predict that $\mathrm{B}$ is justified to answer $p$ without further speculation. While this is in line with the data, B can alternatively interpret A's utterance as an expression of curiosity and remain (unhelpfully) silent. Again, this confirms that silence is a conventionally possible reaction.

Finally, we can explain why verb-final wohl-questions are restricted to contexts where A believes that B does not know the answer. Verb-final questions show non-standard syntax and an additional evidential and are therefore marked in comparison to both, standard questions and standard wohl questions (Levinson 2000). If speaker A wants to know whether $Q$ and believes that the addressee can conjecture the answer, she prefers the standard (wohl) question. Uttering a verb-final wohl question, speaker A implies that she does not believe that $\mathrm{B}$ knows or can conjecture the answer.

It also follows that verb-final questions with wohl do not occur in other non-standard question situations. They cannot be used as rhetorical questions, i.e. when A knows the answer and believes that B also knows the answer. We also predict that verb-final wohl questions are excluded in exam situations: These open the discourse for defeasible inferences based on pooled 
knowledge. In an exam situation, however, A knows the answer and joint speculations are not what the discourse aims at. The prediction is borne out, as verb-final wohl questions in exam situations are unacceptable. ${ }^{36}$

In summary, the analysis predicts that joint speculation and silence are the possible (conventionalized) reaction to verb-final wohl questions in German. The next subsection extends the analysis to verb-final polar questions with the complementizer $o b$.

\subsubsection{Polar verb-final wohl questions}

Polar verb-final questions in German like (63) differ from the wh-questions in that they show $o b$ in $\mathrm{C}^{0}$.

(63) Ob Hein wohl auf See ist?

Unlike the question complementizer $o b$, this ' $o b$ ' occurs in a root clauses without being licensed by a matrix predicate. Its syntactic properties thus differ from standard $o b$ which is restricted to embedded questions. Let us call the entry $o b_{C Q}$ for the moment. I propose that $o b_{C Q}$ has the same denotation as SHARE in $w h$-verb-final questions.

$$
\begin{aligned}
& \llbracket o b_{C Q} \rrbracket^{c}=c^{* *} \\
& \text { where } c^{* *} \text { is derived from } c \text { as in (59) }
\end{aligned}
$$

As a consequence, the $\mathrm{C}^{0}$-head $o b_{C Q}$ is restricted to the same syntactic and semantic environments as SHARE in 4.2.1. At LF, $o b_{C Q}$ takes highest scope above wohl and the question clause. The semantic composition of (63) is illustrated below. The question operator ? derives the polar question meaning and takes scope below wohl and $o b_{C Q}$. The symbol + in (65e) indicates pointwise functional application of characters to $c^{* *}$.

(65) a. [SpecC - [C'ob $b_{C Q}$ [IP Hein wohl auf See ist ? ] ] ]

b. LF: [ ob $b_{C Q}$ [ForceP wohl [SpecC - [C' - [IP ? Hein - auf See ist ]]]]]

c. $\llbracket$ ? Hein auf See ist $\rrbracket^{c}$ $=\{\lambda w \cdot \operatorname{HEIN}-\mathrm{AT}-\operatorname{SEA}(w), \lambda w \cdot \neg \operatorname{HEIN-AT-SEA}(w)\}$

d. $\llbracket$ wohl [ ? Hein auf See ist $] \rrbracket^{c}$ $=\left\{\lambda c \lambda w_{0} . \forall w\left(\operatorname{STEREO}\left(s p(c), w_{0}, q(c), w\right) \rightarrow \operatorname{HEIN-AT-SEA}(w)\right)\right.$, $\left.\lambda c \lambda w_{0} . \forall w\left(\operatorname{STEREO}\left(s p(c), w_{0}, q(c), w\right) \rightarrow \neg \operatorname{HEIN-AT-SEA}(w)\right)\right\}$

36 I thank the reviewers for bringing up the issue. Note that the picture-book scenario in (53) is not an exam situation in the sense that A knows the answer. 
Conjectural questions

$$
\begin{aligned}
& \text { e. } \llbracket o b_{C Q}[\text { wohl }[\text { ? Hein auf See ist }]] \rrbracket^{c} \\
& =\llbracket o b_{C Q} \rrbracket^{c}+\llbracket \text { wohl }[\text { ? Hein auf See ist }] \rrbracket^{c} \\
& =\left\{\lambda w_{0} . \forall w\left(\operatorname{STEREO}\left(s p(c) \oplus a d(c), w_{0}, q_{s p(c)} \wedge q_{a d(c)}, w\right)\right.\right. \\
& \rightarrow \operatorname{HEIN-AT-SEA}(w)) \text {, } \\
& \lambda w_{0} . \forall w\left(\operatorname{STEREO}\left(s p(c) \oplus a d(c), w_{0}, q_{s p(c)} \wedge q_{a d(c)}, w\right)\right. \\
& \rightarrow \neg \operatorname{HEIN-AT-SEA}(w))\}
\end{aligned}
$$

The question denotation can be paraphrased as follows: "What - if we pool our knowledge - would we conjecture? Would you and I together say that Hein is at sea or that Hein is not at sea?" As before, the addressee can react in three ways: Engage in speculative discourse, leave the question unanswered or provide the answer, if known.

In summary, we have an analysis of conjectural verb-final wohl questions in German that builds on the meaning of wohl. Section 2 argued that wohl in assertions is an inferential evidential. I proposed that wohl $p$ conveys that the speaker defeasibly infers $p$ from privileged knowledge $q$. When drawing inferences, speakers take into account their maximal body of knowledge $q$ that pertains to the given issue. They don't make claims that are defeated by their own knowledge. Section 3 transferred the analysis of wohl to standard questions. Building on Lim 2010, 2011, I proposed that wohl $Q$ denotes a set of characters. These anticipate that the addressee provides an answer that rests on defeasible inference, thus predicting the interrogative flip. The flip is effected by the lexical properties of wohl. This is justified by the observation that many, but not all evidentials in questions give rise to interrogative flip.

The present section extended the analysis to verb-final wohl questions. I proposed that they denote sets of possible answers where wohl refers to the plurality of speaker $\mathrm{A}$ and addressee $\mathrm{B}, \mathrm{A} \oplus \mathrm{B}$. If an answer is to be chosen, $A \oplus B$ together have to adhere to the maximality condition. In typical utterance situations for verb-final wohl questions, A has not informed B beforehand about everything he knows about $Q$. Before drawing defeasible inferences, A and B must hence pool relevant knowledge about $Q$. B can react by starting speculative discourse about $Q$. Speculative discourse includes B contributing further knowledge but extends to guessed answers, suggestions or own experience with the issue. Speculative discourse is hence a free way to engage with the question at hand. Alternatively, B can silently acknowledge A's curiosity. In normal utterance contexts, this option might in fact follow from general speech act principles. Among the felicity conditions of requests, Searle (1969: p. 66) lists that '[the speaker] believes [the hearer] is able to do (the requested action) A'. Applying this to the case of standard 
questions, this means that A must believe B to be able to answer the question. In the case of verb-final wohl questions with A knowing beforehand that $\mathrm{B}$ is not able to answer, A violates against these conditions. The present analysis therefore predicts that the utterance doesn't constitute a request for an answer. It is plausible to assume that 'not replying' or 'tacitly acknowledging the utterance' is a reasonable move in this case. Yet, a specific speech act theory that predict permissible (non-)reactions in this case remains to be explored.

The use of verb-final wohl questions in contexts like (62) shows that B's option to remain silent has turned into a conventionalized reaction. ${ }^{37}$ As we saw in example (62), B can remain silent even if A shares knowledge before uttering the question. The option for B to remain silent should thus be viewed as the lexical contribution of SHARE, as suggested in (Roelofsen \& Farkas 2017).

The analysis has several advantages over earlier accounts of conjectural verb-final wohl questions in German. It predicts that wohl is a mandatory part of CQs in German and assumes that wohl plays a mayor role in deriving the pragmatic properties of CQs. The analysis can therefore potentially explain why inferential evidentials in other languages also give rise to CQ readings (see Section 5). The analysis moreover motivates the conventionalized reactions to verb-final wohl questions by their pragmatic properties in typical situations of use (i.e., where A believes B is unable to answer). While the pragmatic profile of CQs can also be successfully captured in terms of conversational scoreboard models (Roelofsen \& Farkas 2015, 2017), the present analysis has the potential to explain why verb-final wohl questions adopt the range of possible reactions that we observe. Finally, the analysis draws a link between CQs and joint speculation. This connection may be worth further pragmatic exploration in the future.

\subsection{Other analyses of conjectural questions}

The present section surveys earlier formal analyses of conjectural questions and compares them to the present account.

Lohnstein 2007, Truckenbrodt 2006 investigate German polar verb-final questions and propose that subordinate clause syntax is their key feature. Both authors start from the assumption that verb movement to $\mathrm{C}^{0}$ is a necessary prerequisite to express a speech act in German. The pragmatic profile

37 See Traugott 1988 and Eckardt 2006 on mechanisms of meaning change. 
of conjectural questions supposedly emerges as the result of two conflicting cues: The speaker utters a question but one that does not express a proper speech act. Roughly speaking, the addressee interprets these cues as "the speaker wonders about Q" and "I am not supposed to do anything about it". Truckenbrodt 2006 models the two cues in terms of syntactic features in ForceP. While the feature epist indicates that speakers want to change their epistemic state, the feature deont indicates that someone is supposed to do something. In verb-final questions, Truckenbrodt proposes, the feature deont is absent and thus the utterance poses no request on the addressee. This offers a good start to account for the fact that German CQs don't pose a request to the addressee. While the analysis captures the difference between standard polar questions and (conjectural) polar verb-final questions, it fails to situate wohl as an obligatory element in conjectural wh-questions (see (55)). It is also challenged by German verb-final questions that do convey requests: Verb-final questions can serve as repeat questions that draw the interlocutor's attention back to an open question (Oppenrieder 1989, Disselkamp 2017). Plunze \& Zimmermann (2006) call into doubt the claim that conjectural questions do not require any reaction by the addressee and point out that "not answering" and "not doing anything" should be kept apart. Finally, the analysis is tailored for German in that subordinate clause syntax is not a triggering feature for conjectural questions in other languages. The present analysis is better suited to understand the interaction between evidentials and the pragmatics of questions, as argued in Section 5. M. Zimmermann (2011) mentions wohl as an element of German conjectural questions and notes a certain harmony between wohl in questions and questions with verb-final syntax, however without detailed analysis.

In Salish languages, inferential evidentials trigger an interpretation as CQ. Littell, Matthewson \& Peterson (2010) propose to capture the meaning of evidentials in terms of the presupposition "the agent has evidence that entails $p_{i}$ ". They argue that each possible answer $p_{i}$ presupposes that the addressee has evidence that entails $p_{i}$. In conclusion, the question as a whole must presuppose that the addressee has evidence in favour of any possible answer $p_{i}$ to the question. This being an unlikely and often a contradictory presupposition, they argue, the addressee is relieved from the obligation to answer. Conjectural questions are viewed as too rich in presuppositions to be answered. The analysis, however, overgenerates because the predicted semantic interaction of evidentials and questions should generalize to other languages. This is problematic as evidentials often trigger the interrogative 
flip instead. It is also open whether the authors would maintain their analysis for Salish inferential evidentials like $k^{\prime} a$ (St'át'imcets), as they argue in other work that evidentials pattern with modal operators (Matthewson, Davis \& Rullmann 2007).

Japanese conjectural questions have been at the focus of attention in a series of papers in recent years. Among those are conjectural questions marked with the evidential morpheme daroo. The syntactic approaches in Sugimura 1986, Miyagawa 2012, Tenny 2006, Oguro 2017 take an extended speech act phrase as their starting point. The presence or absence of daroo as well as honorific markers correlates with the presence or absence of a SpeakerPhrase and HearerPhrase in the sense of Speas \& Tenny 2003. While the account adequately predicts grammatical and ungrammatical questions, the interface to semantics as well as the meaning of conjectural questions remains open. As the authors fail to spell out how syntactic features, pragmatic restrictions and the world relate to each other, it is unclear whether they claim that a sentence without HearerP is ungrammatical in the presence of an addressee (and, vice versa, a sentence with HearerP is ungrammatical in soliloquy). More interesting for the present account is the work by Yurie Hara. (Hara 2006) analyses daroo in declaratives as an inferential evidential and compares its interpretation in assertions to other Japanese evidentials. Hara (2018) proposes a semantic analysis of daroo in conjectural questions in terms of inquisitive semantics (Ciardelli \& Roelofsen 2015). The chosen framework is ideally suited to model discourse where an issue (proposition or question) is in the speaker's mind, disregarding whether a question has been openly posed or not. She assumes that daroo conveys that the denotation of the prejacent is an issue for the speaker, where "issue" in inquisitive semantics covers both declaratives and questions. The complex pattern of Japanese questions and assertions with or without daroo emerges as a joint effect of daroo and an interpretation for sentence accents in Japanese (Hara 2012, Miyagawa 2012). While the analysis correctly predicts the data under investigation, the denotation of daroo no longer contributes the evidential meaning detailed in earlier work (Hara 2006). Evidential assertions of the form daroo S, according to the most recent account in Hara 2018, are synonymous to the proposition 'the speaker knows $S$ '; the observed hedging effect of the evidential is attributed to Gricean implicature.

Gunlogson (2003) initiated a strand of ongoing research on the conversational scoreboard (Farkas \& Bruce 2010, Roelofsen \& Farkas 2017, Farkas 2017, 2020). Farkas and Roelofson envisage a new division of labour between 
Conjectural questions

words that determine semantic content, on one side, and other words or morphemes that determine the functioning of the sentence in discourse, on the other side. Farkas $(2017,2020)$ applies this idea to Romanian conjectural questions with the particle oare. The contribution of oare in questions consists the instruction that the conjectural question may be removed from the table without the addressee providing an answer. She thus predicts that oare questions can remain unanswered without leading to a situation of crisis, and without running the dialogue into an instable state.

Farkas 2020 covers verb-final wohl questions in terms of the conversational scoreboard and makes good predictions for German CQs in questionanswer dialogue (assuming that joint speculation can be explained as a general conversational strategy to deal with questions). However, this kind of analysis leaves open why wohl is the conventionalized cue of CQs in German, and why evidentials are also recruited as cues for CQs in many other languages. The final section addresses this wider panorama.

\section{Outlook: Conjectural questions in other languages}

Surveying the literature on evidential markers, we find four possible uses of evidentials in questions: Evidentials can be oriented to the speaker in questions like in declaratives, as in Eastern Pomo (San Roque, Floyd \& Norcliffe 2017); yet these cases seem rare and yield readings that are difficult to paraphrase. Some languages are reported to exclude evidentials from questions (Samoyedic languages, Aikhenvald 2004a:11, Künnap 2002: p. 149). ${ }^{38}$ In many languages, evidentials in questions show the interrogative flip, reported, for instance, for Qiang (San Roque, Floyd \& Norcliffe 2017), Tsafiki (Aikhenvald 2004b), Nganasan (Uralic, Aikhenvald 2004b), Macedonian (Slavic; Friedman 2003), Turkish (Mericli 2016), Tibetan (Sino-Tibetan; Garrett 2001), Korean (Lim 2011), Cuzco Quechua (Faller 2002), along with German wohl in standard questions.

Finally, evidentials serve to mark CQs in many unrelated languages, including Ecuador Quechua (San Roque, Floyd \& Norcliffe 2017), Gitksan, St'át'imcets and Nełe?kepmxcín (Littell, Matthewson \& Peterson 2010), Cuzco Quechua (Faller 2002), Cheyenne (Murray 2010a,b, 2016), Tariana (Upper Amazon; Aikhenvald 2003), Shipibo-Konibo (Valenzuela 2003), Japanese (Hara 2006, 2018) and Basque (Trotzke \& Monforte 2019). Italian has grammaticized a second reading for future tense in assertions that can be inter-

38 Compare the markedness of English questions like \#where, perhaps, is the key? 
preted as evidential (Mari 2010), which triggers a CQ reading in questions (Eckardt \& Beltrama 2019). (Valenzuela 2003) explicitly points out that CQs in Shipibo-Konibo, like in German, serve to initiate joint speculation on a topic. This intuition seems to extend to other languages (Zucchi, p.c., Taylor, p.c.).

This section sketches an analysis of evidentials as CQ markers, using $\langle e v i d\rangle$ as a cover term. $\langle e v i d\rangle$ cannot be context-freezing, or else we would falsely predict the interrogative flip. In assertions, $\langle e v i d\rangle$ should have a denotation similar to the one assumed for wohl in (21) whereas in questions, the evidential additionally should trigger the change from utterance context $c$ to $c^{* *}$. This can be accounted for by the following additional entry for $\langle e v i d\rangle$, reserved for questions:.

$$
\begin{aligned}
& \llbracket\langle\text { evid }\rangle_{Q} \rrbracket^{c} \\
& =\lambda p . \lambda w_{0} . \forall w\left(\operatorname{STEREO}\left(s p(c) \oplus a d(c), w_{0}, q_{s p(c)} \wedge q_{a d(c)}, w\right) \rightarrow p(w)\right)
\end{aligned}
$$

The proposed $\langle e v i d\rangle_{Q}$ combines pointwise with the question denotation. It contributes the inferential non-at-issue meaning and, at the same time, establishes an utterance context where speaker and addressee are jointly responsible for defeasible inferences. We thus predict that the question invites joint speculation based on pooled knowledge. In brief, $\langle e v i d\rangle_{Q}$ in questions integrates the semantic factors that play out in German. ${ }^{39}$

If we are justified in the assumption that CQs are used when speaker A expects that addressee B cannot answer, and if we are moreover right in hypothesizing that in this case, general laws of speech act theory ensure that A is not requesting B to answer, we will once again expect that in the typical context of use, questions with $\langle e v i d\rangle_{Q}$ do not require B to answer. Extending this pattern, the evidential $\langle e v i d\rangle_{Q}$ will acquire the conventionalized meaning of a CQ marker. The present analysis of German verb-final questions thus provides semantic elements that might be in play in other cases where evidentials mark conjectural questions. We tentatively proposed an independent operator that can turn question meanings into question denotations that allow the range of reactions that are typical for conjectural questions, thus laying out the road map to understanding the contribution of evidentials to conjectural questions in other languages.

39 I do not mean to claim that all inferential evidentials in other languages are necessarily synonymous to wohl. The crucial common factors are defeasible inferencing, anchoring to an agent and interdependence with context and sentence type. 
Conjectural questions

\section{References}

Aikhenvald, Alexandra Y. 2003. A grammar of Tariana, from Northwest Amazonia. Cambridge: Cambridge University Press. https://doi.org/10.1017/ cbo9781107050952.

Aikhenvald, Alexandra Y. 2004a. Evidentiality: Problems and challenges. In Piet van Sterkenburg (ed.), Linguistics today: Facing a greater challenge, 1-29. Amsterdam/ Philadelphia: John Benjamins.

Aikhenvald, Alexandra Y. 2004b. Evidentiality. Oxford: Oxford University Press. Altmann, Hans. 1987. Zur Problematik der Konstitution von Satzmodi als Formtypen. In Jörg Meibauer (ed.), Satzmodus zwischen Grammatik und Pragmatik, 22-56. Tübingen: Niemeyer.

Bayer, Josef \& Hans-Georg Obenauer. 2011. Discourse particles, clause structure, and question types. Linguistic Review 28(4). 449-491. https://doi. org/10.1515/tlir.2011.013.

Ciardelli, Ivano A. \& Floris Roelofsen. 2015. Inquisitive dynamic epistemic logic. Synthese 192(6). 1643-1687. https://doi.org/10.1007/s11229-0140404-7.

Davis, Christopher, Christopher Potts \& Margaret Speas. 2007. The pragmatic values of evidential sentences. Semantics and Linguistic Theory (SALT) 17. 71-88. https://doi.org/10.3765/salt.voio.2966.

den Dikken, Marcel \& Anastasia Giannakidou. 2002. From hell to polarity: "Aggressively non-d-linked" wh-phrases as polarity items. Linguistic Inquiry 33(1). 31-61. https://doi.org/10.1162/o02438902317382170.

Disselkamp, Gisela. 2017. The pragmatics of speaker repeat questions. Poster presentation at ESSLLI. https://typo.uni-konstanz.de/questionsInterfaces/ wp-content/uploads/2018/11/repeat-questions.pdf.

Eckardt, Regine. 2006. Meaning change in grammaticalization. Oxford: Oxford University Press. https://doi.org/10.1093/acprof:oso/97801992626o1. o01.0001.

Eckardt, Regine \& Andrea Beltrama. 2019. Evidentials in questions. Empirical issues in syntax and semantics 12. 121-155. http://www.cssp.cnrs.fr/ eiss12/index_en.html.

Eckardt, Regine \& Gisela Disselkamp. 2019. Self-addressed questions and indexicality: The case of Korean. Sinn und Bedeutung (SUB) 23(1). 383-398. https://doi.org/10.18148/sub/2019.v23i1.539. 
Eckardt, Regine \& Qi Yu. 2020. German bloss questions as extreme ignorance questions. Linguistica Brunensia 68(1). 7-22. https://doi.org/https://doi. org/10.5817/LB202O-1-2.

Faller, Martina. 2002. Evidentials in Cuzco Quechua. Stanford, CA: Stanford University dissertation.

Faller, Martina. 2006. Evidentiality below and above speech acts. Unpublished manuscript. https: / / semanticsarchive. net / Archive / GZiZjBhO / Faller evidentiality.above.below.pdf.

Farkas, Donka. 2017. Going beyond the prototypical: Special interrogatives and special declaratives. Handout for talk at Stanford Colloquium. https: //cpb-us-e1.wpmucdn.com/sites.ucsc.edu/dist/e/439/files/2018/o1/ Handout2up_Stanford-14vxl2b.pdf.

Farkas, Donka. 2020. Canonical and non-canonical questions. UC Santa Cruz manuscript. https://semanticsarchive.net/Archive/WU2ZjIwM/questions. pdf.

Farkas, Donka \& Kim B. Bruce. 2010. On reacting to assertions and polar questions. Journal of Semantics 27(1). 81-118. https://doi.org/10.1093/ jos/ffpoio.

von Fintel, Kai \& Anthony Gillies. 2010. Must... stay... strong! Natural Language Semantics 18(4). 351-383. https://doi.org/10.1007/s11050-0109058-2.

von Fintel, Kai \& Anthony Gillies. 2011. 'Might' made right. In Andy Egan \& Brian Weatherson (eds.), Epistemic modality, 108-130. Oxford: Oxford University Press. https://doi.org/10.1093/acprof:0so/9780199591596.003. oo04.

Friedman, Victor A. 2003. Evidentiality in the Balkans with special attention to Macedonian and Albanian. In Alexandra Y. Aikhenvald \& R.M.W. Dixon (eds.), Studies in evidentiality, vol. 54, 189-218. Amsterdam/Philadelphia: John Benjamins. https://doi.org/10.1075/tsl.54.11fri.

Gabbay, Dov M., C.J. Hogger \& J.A. Robinson. 1994. Nonmonotonic reasoning and uncertain reasoning (Handbook of Logic in Artificial Intelligence and Logic Programming Vol. 3). Oxford \& New York: Oxford University Press.

Garrett, Edward John. 2001. Evidentiality and assertion in Tibetan. University of California Los Angeles dissertation.

Göbel, Alex. 2017. Evidentiality and undirected questions: A new account of the German discourse particle wohl. Presentation at the Penn Linguistics Conference 41. https://alexgoebel.files.wordpress.com/2016/o6/03_25_ 17-plc-talk.pdf. 
Conjectural questions

Göbel, Alex. 2018. Evidentiality and undirected questions: Wohl. University of Pennsylvania Working Papers in Linguistics 24(1). 77-86. https://repository. upenn.edu/pwpl/vol24/issi/10.

Groenendijk, Jeroen \& Martin Stokhof. 1984. Studies on the semantics of questions and the pragmatics of answers. University of Amsterdam dissertation.

Gunlogson, Christine. 2003. True to form: Rising and falling declaratives as questions in English. New York: Routledge. https://doi.org/10.4324/ 9780203502013.

Gutzmann, Daniel. 2011. Ob einer wohl recht hat? Zwei Satzmodustheorien für das Deutsche im Vergleich. Deutsche Sprache 39. 65-84. https://doi. org/10.37307/j.1868-775X.2011.01.05.

Hara, Yurie. 2006. Non-propositional modal meaning. Accessed July 2018. https://www.semanticsarchive.net/Archive/WUxZjFiM/darou_hara.pdf.

Hara, Yurie. 2012. On the interaction among sentence types, bias, and intonation: A rating study. In GLOW in Asia, vol. 9. Poster presentation. http: //faculty.human.mie-u.ac.jp/ glow_mie/glow_IX_index.html.

Hara, Yurie. 2018. Daroo as an entertain modal: An inquisitive approach. Japanese/Korean Linguistics 25. 1-13.

Iatridou, Sabine. 1991. Topics in conditionals. Cambridge, MA: MIT dissertation.

Jang, Youngjun. 1999. Two types of question and existential quantification. Linguistics 37(5). 847-869. https://doi.org/10.1515/ling.37.5.847.

Jang, Youngjun \& Il-Kon Kim. 1998. Self-addressed questions and quantifier interpretation. Korean Linguistics 9. 191-209. https://doi.org/10.1075/kl. 9.07yj.

Kaplan, David. 1989. Demonstratives. In Joseph Almog, John Perry \& Howard Wettstein (eds.), Themes from Kaplan, 481-614. Oxford: Oxford University Press.

Korotkova, Natasha. 2014. Evidentials in attitudes: Do's and don'ts. Sinn und Bedeutung (SuB) 19. 320-337. https://doi.org/10.18148/sub/2015.v19io. 237.

Korotkova, Natasha. 2017. Diagnosing the semantic status of evidentials. Talk at the Questioning speech acts workshop, University of Konstanz. http: //nkorotkova.net/files/korotkova2017-qsa-abstract.pdf.

Kratzer, Angelika. 1991. Modality. In Arnim von Stechow \& Dieter Wunderlich (eds.), Semantics/Semantik. An international handbook, 639-650. Berlin \& New York: De Gruyter. 
Krifka, Manfred. 2004. Semantics below and above speech acts. Paper presented at Stanford University Linguistics colloquium. https://amor.cms. hu-berlin.de/ h2816i3x/Talks/StanfordLecture2004.pdf.

Künnap, Ago. 2002. In Main language shifts in the Uralic languages (LINCOM Studies in Asian Languages (LSIAS) 45). München: LINCOM.

Levinson, Steven. 2000. Presumptive meanings. Cambridge, MA: MIT Press. https://doi.org/10.7551/mitpress/5526.001.0oo1.

Lewis, David. 1973. Counterfactuals. Oxford: Blackwell.

Lim, Dong Sik. 2010. Evidentials and interrogatives: A case study from Korean. Los Angeles, CA: University of Southern California dissertation.

Lim, Dong Sik. 2011. Evidentials in interrogatives. Sinn und Bedeutung (SuB) 15. 419-433. https://ojs.ub.uni-konstanz.de/sub/index.php/sub/article/ view/390.

Lim, Dong Sik \& Chungming Lee. 2012. Perspective shifts of Korean evidentials and the effect of contexts. Semantics and Linguistic Theory (SALT) 22. 26-42. https://doi.org/10.3765/salt.voio.2648.

Link, Godehard. 1983. The logical analysis of plurals and mass terms: A latticetheoretical approach. In Rainer Bäuerle, Christoph Schwarze \& Arnim von Stechow (eds.), Meaning, use, and interpretation of language (Grundlagen der Kommunikation und Kognition), 302-323. Berlin: de Gruyter.

Littell, Patrick, Lisa Matthewson \& Tyler Peterson. 2010. On the semantics of conjectural questions. In Tyler Peterson \& Uli Sauerland (eds.), Evidence from evidentials, 89-104. Vancouver, BC: UBCWPL.

Lohnstein, Horst. 200o. Satzmodus-kompositionell: Modusphrase im Deutschen. Berlin, New York: Akademie Verlag.

Lohnstein, Horst. 2007. On clause types and sentential force. Linguistische Berichte 209. 63-86.

Mari, Alda. 2010. On the evidential nature of the Italian future. Institut JeanNicod. Paris. https://jeannicod.ccsd.cnrs.fr/ijn_oo678549.

Matthewson, Lisa, Henry Davis \& Hotze Rullmann. 2007. Evidentials as epistemic modals: St'át'imcets. The Linguistic variation yearbook $7(1)$. https: //doi.org/10.1075/livy.7.07mat.

McCready, Elin \& Norry Ogata. 2007. Evidentiality, modality and probability. Linguistics and Philosophy 30(2). 147-206. https://doi.org/10.1007/ s10988-007-9017-7.

Mericli, Benjamin Stephen. 2016. Modeling indirect evidence. University of California at Los Angeles MA thesis. 
Conjectural questions

Miyagawa, Shigeru. 2012. Agreements that occur mainly in the main clause. In Lobke Aelbrecht, Liliane Haegeman \& Rachel Nye (eds.), Main clause phenomena: New horizons, 79-112. Amsterdam/ Philadelphia: John Benjamins. https://doi.org/10.1075/la.190.04miy.

Murray, Sarah. 2009. A Hamblin semantics for evidentials. Semantics and Linguistic Theory (SALT) 19. 324-341. https://doi.org/10.3765/salt.voio. 2543.

Murray, Sarah. 2010a. Evidentiality and the structure of speech acts. New Brunswick, NJ: Rutgers University dissertation.

Murray, Sarah. 2010b. Evidentials and questions in Cheyenne. Semantics of Under-Represented Languages in the Americas (SuLA) 5. 139-155.

Murray, Sarah. 2014. Varieties of update. Semantics and Pragmatics 7(2). 153. https://doi.org/10.3765/sp.7.2.

Murray, Sarah. 2016. Evidentiality and illocutionary mood in Cheyenne. International Journal of American Linguistics 82(4). 487-517. https://doi.org/ 10.1086/688604.

Obenauer, Georg. 2004. Non-standard wh-questions and alternative checkers in Pagotto. In Horst Lohnstein \& Susanne Trissler (eds.), The syntax and semantics of the left periphery, 343-384. Amsterdam: John Benjamins.

Oguro, Takeshi. 2017. Speech act phrase, conjectural questions, and hearer. University of Pennsylvania Working Papers in Linguistics 23(1). https:// repository.upenn.edu/pwpl/vol23/iss1/22/.

Oppenrieder, Wilhelm. 1989. Selbständige Verb-letzt-Sätze: Satzmodussystem und ihre intonatorische Kennzeichnung. In Hans Altmann, Anton Batliner \& Wilhelm Oppenrieder (eds.), Zur Intonation von Modus und Fokus im Deutschen, 163-244. Tübingen: Niemeyer.

Peterson, Tyler. 2016. Mirativity as surprise: Evidentiality, information, and deixis. Journal of Psycholinguistic Research 45. 1327-1357. https:// doi. org/10.1007/s10936-015-9408-9.

Peterson, Tyler, Uli Sauerland \& Rose-Marie Déchaine. 2010. Evidence from evidentials: Introduction. In Tyler Peterson \& Uli Sauerland (eds.), Evidence from evidentials (University of British Columbia Working Papers in Linguistics 28), 1-8. Vancouver: UBCWPL. https://www.public.asu.edu/ $\sim$ trpete13/papers/evidentials.pdf.

Plunze, Christian \& T. Ede Zimmermann. 2006. On Truckenbrodt on verb-end questions. Theoretical Linguistics 32(3). 321-333. https://doi.org/10.1515/ TL.2006.020. 
Potts, Christopher. 2005. The logic of conventional implicatures. Oxford: Oxford University Press.

Rawlins, Kyle. 2009. A semantics for extreme ignorance questions. Presentation at Linguistic Society of America Annual Meeting. https://rawlins.io/ downloads/various/rawlins_lsa_20o9_eiqs.pdf.

Roelofsen, Floris \& Donka Farkas. 2015. Polarity particle responses as a window onto the interpretation of questions and assertions. Language 91(2). 359-414. https://doi.org/10.1353/lan.2015.0017.

Roelofsen, Floris \& Donka Farkas. 2017. Division of labor in the interpretation of declaratives and interrogatives. Journal of Semantics 34(2). 237-289. https://doi.org/10.1093/jos/ffwo12.

San Roque, Lila, Simeon Floyd \& Elisabeth Norcliffe. 2017. Evidentiality and interrogativity. Lingua 186/187. 120-143. https:// doi.org/10.1016/j . lingua.2014.11.003.

Schlenker, Philippe. 2018. Indexicals. In Sven Ove Hansson \& Vincent F. Hendricks (eds.), Introduction to formal philosophy, 297-321. New York, NY: Springer. https://doi.org/10.1007/978-3-319-77434-3_14.

Searle, John. 1969. Speech acts. Cambridge: Cambridge University Press.

Speas, Margaret \& Carol L. Tenny. 2003. Configurational properties of point of view roles. In Anna Maria Di Sciullo (ed.), Asymmetry in grammar, 315345. Amsterdam/Philadelphia: John Benjamins. https://doi.org/10.1075/ la.57.15spe.

Strasser, Christian \& Aldo G. Antonelli. 2016. Non-monotonic logic. In Edward N. Zalta (ed.), The Stanford encyclopedia of philosophy, Winter 2016. https: //plato.stanford.edu/archives/win2016/entries/logic-nonmonotonic/.

Sugimura, R. 1986. Japanese honorifics and situation semantics. In Proceedings of COLING, vol. 86, 507-510. https://doi.org/10.3115/991365.991514.

Tenny, Carol L. 2006. Evidentiality, experiencers, and the syntax of sentience in Japanese. Journal of East Asian Linguistics 15. 245-288. https://doi. org/10.1007/s10831-006-0002-x.

Tenny, Carol L. \& Margaret Speas. 2004. The interaction of clausal syntax, speech act roles, and information structure in questions. Presentation at Workshop on Syntax, Semantics and Pragmatics of Questions, ESSLLI 2004. http://www.linguist.org/ESSLI-Questions-hd.pdf.

Thurmair, Maria. 1989. Modalpartikeln und ihre Kombinationen. Tübingen: Niemeyer. https://doi.org/10.1515/9783111354569. 
Conjectural questions

Traugott, Elizabeth Closs. 1988. Pragmatic strengthening and grammaticalization. Berkeley Linguistics Society (BLS) 14. 406-416. https://doi.org/ 10.3765/bls.v14io.1784.

Trotzke, Andreas \& Sergio Monforte. 2019. Basque question particles: Implications for a syntax of discourse particles. Linguistic Variation 19(2). 352385. https://doi.org/10.1075/lv.18002.tro.

Truckenbrodt, Hubert. 2006. On the semantic motivation of syntactic verb movement to C in German. Theoretical Linguistics 32. 257-306. https:// doi.org/10.1515/tl.2006.018.

Truckenbrodt, Hubert. 2013. Selbständige Verb-Letzt-Sätze. In Jörg Meibauer, Markus Steinbach \& Hans Altmann (eds.), Satztypen im Deutschen, 232246. Berlin: de Gruyter Mouton.

Valenzuela, Pilar M. 2003. Evidentiality in Shipibo-Konibo, with a comparative overview of the category in Panoan. In Alexandra Y. Aikhenvald \& R. M. W. Dixon (eds.), Studies in evidentiality, 33-61. Amsterdam: John Benjamins. https://doi.org/10.1075/tsl.54.05val.

Willett, Thomas. 1988. A cross-linguistic survey of the grammaticization of evidentiality. Studies in Language 12. 51-97.

Zimmermann, Malte. 2004. Zum 'Wohl': Satztypmodifikatoren. Linguistische Berichte 199. 253-286.

Zimmermann, Malte. 2008. Discourse particles in the left periphery. In Benjamin Shaer, Philippa Cook, Werner Frey \& Claudia Maienborn (eds.), Dislocated elements in discourse, 208-239. London: Routledge.

Zimmermann, Malte. 2011. Discourse particles. In Klaus von Heusinger, Claudia Maienborn \& Paul Portner (eds.), Semantik/Semantics: An international handbook, vol. 2, 2012-2038. Berlin: de Gruyter. https://doi.org/10.1515/ 9783110255072.2012.

Zimmermann, Malte. 2013. Ob-VL-Interrogativsatz. In Jörg Meibauer, Markus Steinbach \& Hans Altmann (eds.), Satztypen im Deutschen, 84-104. Berlin: de Gruyter Mouton.

Zimmermann, T. Ede. 2012. Context dependence. In Klaus von Heusinger, Claudia Maienborn \& Paul Portner (eds.), Semantik/Semantics. An international handbook, vol. 3, 236o-2407. Berlin: deGruyter Mouton. https: //doi.org/10.1515/9783110589849-012. 
Regine Eckardt

Regine Eckardt

Universitätsstrasse 10

Fach 191

D-78464 Konstanz

regine.eckardt@uni-konstanz.de 